\title{
El campo de estudios de la integración regional y su aporte a las Relaciones Internacionales: una mirada desde América Latina
}

\author{
Daniela Vanesa Perrotta*
}

\begin{abstract}
Resumen
El trabajo se organiza en base a tres objetivos: primero, analizar los aportes del estudio de la integración regional a las Relaciones Internacionales; segundo, presentar las contribuciones latinoamericanas al campo de estudio de la integración; tercero, analizar la actual discusión disciplinar sobre el desarrollo de las Relaciones Internacionales desde la contribución de la academia latinoamericana. En esto último se incorporan discusiones sobre el uso del conocimiento social y su articulación con las políticas públicas. A lo largo del trabajo se presentan argumentos para cada objetivo. Especialmente para el segundo se afirma que el pensamiento latinoamericano para la integración ha sido generado en redes regionales de producción de conocimiento y constituye un aporte novedoso al campo de estudios. Respecto del tercero, el argumento que se sostiene es que la discusión sobre la globalidad, globalización o internacionalización de la disciplina -abierto hace un tiempo escaso-, aun presenta reflexiones modestas que poco abonan a la identificación de la problemática central: cómo se produce conocimiento en Relaciones Internacionales, la delimitación de centros y periferias y sus diferentes problemas cognitivos y las consecuentes situaciones de dependencia académica.
\end{abstract}

\section{Palabras clave}

Relaciones Internacionales; Integración Regional; Regionalismo; Teorías de la Integración; Nuevo Regionalismo; América Latina; Colegios Invisibles; Ciencia Encargada.

\section{TITLE}

The field of studies of regional integration and its contribution to International Relations: a look from Latin America

\begin{abstract}
The paper is organized based on three objectives: first, to analyze the contributions of the study of regional integration to International Relations; second, to present Latin American contributions to the field of study of integration; third, to analyze the current disciplinary discussion on the development of International Relations from the perspective of the contribution of the Latin American academy. Regarding this last issue, discussions on the use of social knowledge and its articulation with public policies are incorporated. Throughout the work, we present arguments for each objective. Especially for the second we argue that Latin American thought for integration has been generated in regional knowledge networks and constitutes a novel contribution to the field of studies. Regarding the third, the argument that arises is that the discussion on the globalism, globalization or internationalization of the discipline - recently posed, still presents modest reflections that pay little attention to the identification of the central problem: how knowledge in International Relations is produced, the delimitation of centers and peripheries and their different cognitive problems and the consequent situations of academic dependence.
\end{abstract}

\section{KEYWORDS}

International Relations; Regional integration; Regionalism; Theories of Integration; New Regionalism; Latin America; Unseen Science; Mandated Science
*Daniela Vanesa PERROTTA, Universidad de Buenos Aires (UBA), Consejo Nacional de Investigaciones, Científicas y Técnicas (CONICET), Consejo Latinoamericano de Ciencias Sociales (CLACSO)-

Recibido:

14-02-2018

Aceptado:

15-06-2018

DOI:

https://doi. org/10.15366/relacionesinternacionales2018.38.001

\section{Agradecimientos:} La autora agradece las sucesivas lecturas y los comentarios enriquecedores de Emanuel Porcelli y Mauro Alonso.

Financiamiento: Este trabajo se ha desarrollado en el marco del proyecto de investigación que dirijo: UBACYT Modalidad II (2016-2018) "La integración regional latinoamericana como campo de estudios" (código 20020150200099BA) radicado en el Centro de Estudios en Ciudadanía, Estado y Análisis Político (CEAP) de la Facultad de Ciencias Sociales de la UBA. 


\section{ntroducción}

La amplia y diversa gama de experiencias históricas de integración regional en todo el mundo permite señalar que no existe una forma única de encaminar proyectos de construcción de región. El mosaico de explicaciones sobre regiones, integración y regionalismo es caleidoscópico. No obstante, tampoco es deseable la existencia de tantas formulaciones teóricas como proyectos regionales. Por lo tanto, la delimitación conceptual ha sido una preocupación constante. Las variadas experiencias comparten un conjunto de características comunes que las diferencian de otras formas de cooperación, coordinación o concertación interestatales: la creación de instituciones comunes para adoptar decisiones consensuadas que generan normas que afectan el nivel nacional de regulación de políticas. Vale destacar que (1) la puesta en común y/o sesión de soberanía no ha de ser idéntica en todos los casos, (2) la regulación regional sobre la agenda doméstica puede variar en profundidad y alcance, y (3) no todos los acuerdos avanzan necesariamente en la conformación de una narrativa común que proporcione un horizonte de significado compartido sobre el proyecto político subyacente que erige a la región en tanto actor.

Con todo, la creación, el estudio y la evaluación de esquemas de integración regional ha estado influenciada por dos modelos que adquirieron estatus distinguidos: el europeo ${ }^{1}$ y el regionalismo nuevo o abierto ${ }^{2}$. Así, buena parte de los acuerdos regionales creados entre los años sesenta y principios de los noventa del siglo XX fueron evaluados exhaustivamente en términos de cuánto se parecía o difería respecto de la experiencia de integración de Europa occidental. De la misma manera, el nuevo regionalismo prescribió la forma deseada de sortear los desafíos de una globalización competitiva desde mediados de los años noventa. El primero, se diseminó como parte de la estrategia de política exterior de la actual Unión Europea $(U E)^{3}$. El segundo formó parte del repertorio de prescripciones de políticas de un conjunto de organismos financieros internacionales ${ }^{4}$. Mientras en el primero la nota distintiva versó en la cesión de soberanía en diversas agendas de política pública, el segundo se concentró en la regulación del comercio internacional para promover la liberalización de bienes, servicios, inversiones, propiedad intelectual y compras públicas. El análisis crítico de la integración regional parte de reconocer que los enfoques, teorías, constructos y metodologías disponibles

1 Las alusiones a Europa señalan a la actual Unión Europea.

2 Nos referimos aquí al tipo histórico de regionalismo denominado como nuevo, para diferenciar de los primeros procesos de construcción de región (viejo regionalismo) y no a la corriente teórica homónima. También abordado como regionalismo abierto.

3 BÖRZEL, Tanja y RISSE, Thomas, "Diffusing (inter-) regionalism. The EU as a model of regional integration," Working Paper KFG The Transformative Power of Europe, 2009; BÖRZEL, Tanja y RISSE, Thomas, "When europeanisation meets diffusion: Exploring new territory" en West European Politics, vol. 35, no 1, 2011; JETSCHKE, Anja y LENZ, Tobias, "Does regionalism diffuse? A new research agenda for the study of regional organizations" en Journal of European Public Policy, vol. 20, no 4, 2013; HAASTRUP, Toni, "EU as mentor? Promoting regionalism as external relations practice in EU-Africa relations" en Journal of European Integration, vol. 35, no 7, 2013.

4 BID, "El nuevo regionalismo en américa latina" Mas Allá de las Fronteras: El Nuevo Regionalismo en América Latina, Banco Interamericano de Desarrollo, BID Buenos Aires, 2002; CEPAL, Transformación Productiva con Equidad. La Tarea Prioritaria de América Latina y el Caribe en los Años Noventa, CEPAL, Santiago de Chile, 1990, PANAGARIYA, Arvind, The New Regionalism in Trade Policy World Bank Publications, 1992, DE MELO, Jaime y PANAGARIYA, Arvind, New Dimensions in Regional Integration Cambridge University Press, 1995; BHAGWATI, Jagdish y PANAGARIYA, Arvind, "Preferential trading areas and multilateralism-strangers, friends, or foes" en BHAGWATI, Jagdish N.; KRISHNA, Pravin y PANAGARIYA, Arvind, (eds.) Trading Blocs: Alternative Approaches to Analyzing Preferential Trade Agreements,: MIT Press, Cambridge, 1999; FRANKEL, Jeffrey; STEIN, Ernesto y WEI, Shang-Jin, "Trading blocs and the Americas: The natural, the unnatural, and the super-natural" en Journal of Development Economics, vol. 47, no 1, 1995. 
para el estudio de la construcción de regiones se elaboran en redes centrales y periféricas de producción de conocimiento -conforme la actual geopolítica del conocimiento- ${ }^{5}$. Asimismo, la complejidad del fenómeno regional permite abordarlo como campo de estudios dentro de las ciencias sociales ${ }^{6}$, que tiene una presencia gravitante de académicos de las Relaciones Internacionales, pero que no se agota en esta disciplina7. Un campo es un sistema autónomo de relaciones sociales de fuerza que está determinado por la producción y control de formas específicas de capital simbólico, que según unas particulares reglas de juego, configura posiciones dominantes o dominadas, y en su estructuración se constituye la estructura social. El campo científico se articula en torno a la autoridad científica y la lucha se cimienta sobre el monopolio de la competencia científica ${ }^{8}$. La hegemonía del campo está dada en torno al paradigma que se erige como dominante donde el balance de poder es permanentemente inestable 9 .

Considerando la coexistencia de paradigmas en pugna pero reconociendo la presencia de abordajes hegemónicos y subordinados así como la permanencia de aspectos residuales y emergentes, donde lo que se abandona permanece en cierto estado y lo emergente se comprende en el marco de ello, la explicación de Kuhn es válida para comprender los cambios en los paradigmas del campo de conocimiento de la integración regional. Los paradigmas en disputa por la hegemonía del campo (las vertientes de estudios sobre la integración europea y del nuevo regionalismo), no se abandonan para ser sustituidos. Al contrario, los dos paradigmas se desarrollaron en paralelo hasta el momento reciente de agitación conceptual que fomentó el diálogo entre ambas perspectivas, en pos de una solución de síntesis.

Recapitulando, el estudio de la integración como campo de conocimiento cuenta con dos explicaciones paradigmáticas que ganaron autoridad científica y se encuentra en los últimos años atravesando una crisis. Las formulaciones realizadas desde una perspectiva latinoamericanista se han caracterizado por su carácter periférico y escasa visibilidad. La crisis paradigmática iniciada en el centro desde el año 2008 ha permitido que ganen legitimidad y autoridad explicativa (así como validez y pertinencia) un conjunto de postulados

5 BEIGEL, Fernanda, "Centros y periferias en la circulación internacional del conocimiento" en Nueva Sociedad, no 245, 2013, pp. 110-123; PERROTTA, Daniela, "Universidad y geopolítica del conocimiento" en Revista Ciencias Sociales, no 94, 2017.

6 PERROTTA, Daniela, "La integración regional en américa del sur como objeto de estudio: ¿en pos dela construcción de un campo? " en III Jornadas de Relaciones Internacionales, 2012; PERROTTA, Daniela, "El regionalismo de la educación superior en el proceso de integración regional del mercosur: Políticas de coordinación, complementación, convergencia y armonización en las iniciativas de acreditación de la calidad de carreras de grado (1998-2012)" en Facultad Latinoamericana de Ciencias Sociales, sede académica Argentina, 2013.

7 La inspiración para realizar este tipo de abordaje surge del estudio de Alejandro Simonoff sobre el campo de conocimiento de la Política Exterior Argentina y que utilizamos en trabajos anteriores. SIMONOFF, Alejandro, Teorías en Movimiento. Los Orígenes Disciplinares de la Política Exterior y sus Interpretaciones Históricas, Prohistoria Ediciones, Rosario, 2012.

8 BOURDIEU, Pierre, El Oficio de Científico. Ciencia de la Ciencia y Reflexividad, Anagrama, Barcelona, 2003; BOURDIEU, Pierre, Intelectuales, Política y Poder, Eudeba, Buenos Aires, 2009; REYES VELÁSQUEZ, Carlos, "Sociología del conocimiento: Elementos introductorios desde Pierre Bourdieu para pensar los problemas de construcción y consolidación del campo comunicológico crítico" en Perspectivas de la Comunicación, vol. 6, n² 2, 2013.

9 Los paradigmas son realizaciones científicas universalmente reconocidas que, durante cierto tiempo, proporcionan modelos de problemas y soluciones a una comunidad científica, ya que tienen más éxito que sus competidores para resolver problemas que el grupo de profesionales reconoce como graves. La posición exitosa no implica per se el éxito completo en la resolución de un problema determinado o resultados suficientemente satisfactorios. KUHN, Thomas, La Estructura de las Revoluciones Científicas, Fondo de Cultura Económica, México DF, 1971, p. 51. 
sobre las maneras propias de construcción de región en América Latina que se encuentran en condiciones de disputar, al menos tentativamente, la preeminencia de visiones centrales como parte de un proceso de revalorización de la producción local de conocimiento. Esta situación propia de este campo de estudios se combina, luego, con una reflexión disciplinar en Relaciones Internacionales sobre los saberes subordinados.

Con todo, este artículo tiene tres objetivos: 1) analizar los aportes del estudio de la integración a las Relaciones Internacionales, formulados en redes centrales, 2) presentar las contribuciones latinoamericanas al estudio de la integración y 3) sus efectos recientes sobre la discusión disciplinar. Para ello se presentan las dos redes centrales de producción de conocimiento, primero, y la red periférica latinoamericana, luego ${ }^{10}$.

Respecto del primer objetivo, tres momentos signan la visibilización del estudio de regiones en las Relaciones Internacionales, momentos que se corresponden con los "tipos históricos" de construcción de región ensayados a nivel mundial. Primero, el proceso de IR (integración regional) de Europa Occidental en el período inmediatamente posterior a la II Guerra Mundial marca el inicio de las Teorías de la Integración Regional, desarrolladas por académicos de Relaciones Internacionales descolocados por este fenómeno. Segundo, a mediados de los años noventa la construcción de regiones recupera su popularidad en la disciplina a partir de dos procesos y sus correspondientes formulaciones. Por un lado, el avance de la integración europea a nuevas áreas y niveles de regulación, la multiplicidad de actores involucrados en los complejos procesos de toma de decisiones, la construcción y proyección de su identidad en tanto poder normativo - entre otros factores- estimularon el surgimiento de diferentes TIR, que acompasaron los debates disciplinares. Por otro lado, la creación de múltiples y diversos acuerdos regionales en todo el globo y su vinculación con el proceso de globalización, provocaron el desarrollo de una nueva corriente teórica que, hacia fines de la década, adopta el nombre de Teorías del Nuevo Regionalismo. A partir de entonces se bifurca el campo de estudios de la integración en dos corrientes teóricas que se desarrollarán en paralelo y con escaso diálogo entre sí. Un común denominador a ambas es la incorporación de postulados constructivistas. En tercer lugar, en los últimos años ganó popularidad - nuevamente- para las RI (Relaciones Internacionales) el estudio de las regiones como corolario de la agitación conceptual en el campo, habilitando el diálogo y la búsqueda de acuerdos para una agenda de elaboración de teoría ${ }^{11}$.

El desarrollo de este tercer momento permite desplegar el campo de estudios de la integración en América Latina, en tanto gana visibilidad y popularidad en el circuito central de producción de conocimiento desde la discusión por la apropiación de saberes locales ${ }^{12}$.

${ }^{10}$ Aclaración válida para todo el documento: para cada perspectiva a presentar se escogen sólo algunos autores que expresan una determinada posición -omitiendo otros que realizan aportes similares-. Esto se debe tanto a cuestiones argumentativas de síntesis para un artículo de estas características como por un criterio de "saturación teórica".

${ }^{11}$ La idea de agitación conceptual que postulamos refiere a la conjunción de dos procesos a partir de los años 20082010: por un lado, la integración europea inicia una etapa de crisis en múltiples dimensiones que impactan en la construcción de conocimiento ya que se mostró su imposibilidad para anticipar y explicar estos procesos. Por otro lado, el auge y dinamismo del regionalismo en otras partes del globo -América Latina, Asia y África- habilitó el ensayo de respuestas autónomas de construcción de conocimiento que ganaron popularidad, cuestionaron los postulados del centro y revalorizaron aportaciones locales. PERROTTA, Daniela, El Regionalismo... op.cit., p. 20. Luego, este movimiento de contestación al mainstream disciplinar ganará más peso como parte de la discusión por la incorporación de enfoques subordinados en la disciplina.

12 Por local aludimos a su acepción más sencilla de perteneciente o relativo a un lugar, en este caso, un país o la 
Sostenemos que el pensamiento latinoamericano para la integración ha sido generado en redes regionales de producción de conocimiento y constituye un aporte novedoso al campo de estudios. Los organismos y redes de conocimiento regionales han sido prolíficos en los tres momentos señalados, si bien destacan, por su gravitación, el inicial y el más reciente. El primero, en tanto coincide y es parte constitutiva del proceso de institucionalización de la Ciencia Social en la región. El último, porque en el marco de la agitación conceptual se combina la revitalización de las ideas gestadas en el momento inicial con los impactos de las actuales condiciones de producción de conocimiento sobre la academia local -a partir de la búsqueda de prestigio y reconocimiento en las redes centrales: a veces desde posiciones autonómicas, otras desde un renovado cientificismo- ${ }^{13}$.

Esto sienta las bases para el tercer objetivo del trabajo: reflexionar sobre la actual discusión disciplinar - reflexión que ha madurado en los últimos años- a partir de una de sus derivas, propuesta de Relaciones Internacionales Globales y las contribuciones que se generan desde el Sur Global, especialmente en regiones periféricas. El argumento que se sostiene es que la discusión sobre la globalidad, globalización o internacionalización de la disciplina - abierto hace un tiempo escaso-, aun presenta reflexiones modestas que poco abonan a la identificación de la problemática central: cómo se produce conocimiento en Relaciones Internacionales, la delimitación de centros y periferias y sus diferentes problemas cognitivos y las consecuentes situaciones de dependencia académica.

\section{El circuito central: las teorías de la integración europea y las teorías del nuevo regionalismo}

La integración se vuelve un objeto de estudio a partir de la creación de un arreglo regional único en su tipo en el período inmediatamente posterior a la Segunda Guerra Mundial y su desarrollo, estimulando la curiosidad de numerosos académicos a raíz del desconcierto que generaron sus rasgos salientes ${ }^{14}$. A partir de entonces se crea la Teoría de la Integración Regional, genérico que debe ser apuntado como teorías de la integración europea: el campo de reflexión sistemática sobre el proceso de intensificación de la cooperación política en Europa y el desarrollo de instituciones políticas comunes (y los productos derivados de éstas) y la teorización de las construcciones cambiantes de las identidades y los intereses de los

región latinoamericana. No nos referimos a la discusión sobre el nivel local como subnacional.

${ }^{13}$ El cientificismo es una categoría desarrollada por Oscar Varsavsky para caracterizar un modo de hacer ciencia desvinculado de la problematización política de dicha práctica. Es decir, es una forma de hacer ciencia desvinculada de la sociedad. El cientificista es aquel investigador que se ha adaptado al mercado científico y renuncia a preocuparse por el significado social de su actividad, desvinculándola de los problemas políticos y aceptando de manera acrítica las normas y valores de los grandes centros internacionales de producción de conocimiento. Así, el cientificismo refuerza la dependencia cultural y económica respecto de los países centrales. En el caso de los países dependientes, este tipo de científico es un frustrado perpetuo: para ser aceptado en los "altos círculos" de la ciencia, debe dedicarse a temas más o menos de moda; pero, en tanto las modas se implantan en el Norte, siempre su tarea comienza con desventaja de tiempo. En este contexto, su estrategia de inserción es mantener lazos estrechos con las redes centrales desde una posición subordinada, conformándose con trabajos complementarios de los que allí se producen. VARSAVSKY, Oscar, Ciencia, Política y Cientificismo, Centro Editor de América Latina (CEAL), Buenos Aires, 1969. Cabe aclarar que el cientificismo también ha sido definida por Habermas como la fe en la ciencia en ella misma: es decir, la convicción de que ya no podemos entender la ciencia como una forma de saber posible sino que más bien debemos identificar el saber con la ciencia. HABERMAS, Jurgen, Legitimation Crisis, Beacon Press, Boston, 1973. Tomado de NAIDORF, Judith y PERROTTA, Daniela, "La Ciencia social politizada y móvil de una nueva agenda latinoamericana orientada a prioridades" en Revista de la educación superior, vol. 44, no 174, 2015, pp. 19-46.

${ }^{14}$ La cesión de soberanía en instituciones con rasgos supranacionales que derivó en un proceso de autoreforzamiento y autonomización respecto de los estados nación que las crearon. 
actores sociales que participan de este proceso ${ }^{15}$.

Se han propuesto diferentes periodizaciones del desarrollo de las teorías de la integración europea en función de las preguntas que buscan responder, su ontología y su alcance ${ }^{16}$. Sintetizando estas posturas es posible afirmar el desarrollo de al menos cuatro fases en la construcción de conocimiento sobre la IR de Europa (Occidental). Las fases no implican que las diferentes teorías sean sustituidas conforme se crean nuevas explicaciones; al contrario, estas se van adicionando, perfeccionando y su uso puede disminuir o aumentar. Las primeras teorías se preguntan por qué se produjo la integración europea y cómo se comprenden los resultados del proceso (1960s-1970s): el neofuncionalismo, primero y el intergubernamentalismo, luego, fueron elaboradas por académicos de las RI, parten de una ontología racionalista y aspiran ser teorías generales capaces de aprehender el fenómeno en su totalidad. Se interrogaron respecto de la conducción del proceso (¿los estados o las instituciones comunitarias?) y los actores con capacidad de incidencia (¿cuáles son las élites que pugnan por la construcción de región?; ¿cómo se forman las preferencias?; ¿cómo se ejerce esa presión?).

La segunda etapa analiza la forma peculiar de gobernanza del proceso europeo a partir de interrogarse sobre el tipo de sistema político, las características del proceso decisional y del funcionamiento de las políticas regulatorias de la UE (desde mediados de los años 1980s en adelante): comienza a ser diversificada la procedencia disciplinar de los académicos, especialmente incorporando la Ciencia Política (política comparada) y la Economía (política) y se reconoce la parcialidad de las explicaciones - aspirando a la construcción de teorías de alcance medio-. Se mantiene la ontología racionalista en los nuevos enfoques: enfoques de la gobernanza (especialmente, la multinivel), neoinstitucionalismos -elección racional, histórico y sociológico-, redes de políticas y europeización. Las explicaciones "tradicionales" son revisadas.

La tercera etapa busca entender las consecuencias sociales y políticas que se desprenden del desarrollo de la integración (desde los años 1990s). La procedencia disciplinar adiciona académicos de la Sociología, la Antropología y la Psicología. La discusión gravitante refiere a la discusión ontológica, primero y de la construcción de verdad, luego. Se destacan los siguientes enfoques aplicados al estudio de la integración: el Constructivismo, la Teoría Crítica, las Teorías de género; así como la incorporación de variantes constructivistas en algunos de los enfoques señalados como segunda etapa.

Finalmente, con el contexto de crisis surge una cuarta fase, aún en curso, para explicar las diferentes dimensiones en las que esas múltiples crisis se despliegan pero que también provocó el cuestionamiento a las teorías existentes y la necesidad de encaminar un proceso

${ }^{15}$ WIENER, Antje y DIEZ, Thomas, (eds.) European Integration Theory, Oxford University Press, Oxford, 2004.

${ }^{16}$ WIENER, Antje y DIEZ, Thomas, European... op.cit.; CAPORASO, James y KEELER, John, "The european community and regional integration theory" paper presented at the third biennial international conference of the European Community Studies Association, Washington D.C., 27-29 de mayo de 1993; CHECKEL, Jeffrey, "The constructivist turn in international relations theory" en World Politics, vol. 50, no 2, 1998, pp. 545-560; CHECKEL, Jeffrey, "Social construction and integration" en Journal of European Policy, vol. 6, n 4, 1999, pp. 324-348; DUR, Andreas y GONZÁLEZ, Gemma, "¿Más hombres ciegos y más elefantes? Una revisión de la literatura más reciente sobre la integración europea", Working Paper n० 233 del Institut de Ciències Polítiques i Socials de la Universidad Autónoma de Barcelona, 2004. 
de reflexión más amplio y abierto a propuestas del corpus rival. Surgen interrogantes respecto de la supervivencia y la capacidad de resiliencia de los acuerdos regionales.

Con todo, el aporte del estudio de la integración a las RI se plasma en al menos a tres grandes temáticas: primero, discutir la noción de soberanía estatal y la posibilidad de su cesión y/o puesta en común; segundo, analizar la mutua vinculación entre la política doméstica y la política exterior y cómo las regulaciones regionales inciden en los marcos jurídicos-normativos-políticos nacionales; tercero, arrojar luz sobre la conformación identitaria y social de los procesos de integración - desde la modificación de lealtades y expectativas hasta procesos de socialización regionales-. Son tres ejes que se vinculan al estudio de la creación y mantenimiento de instituciones supranacionales que cuentan con características de estatidad pero no son per se mega o supra estados. Desde la disciplina se busca la delimitación conceptual, especialmente con la noción de regímenes y la categoría cooperación; pudiendo agregar recientemente, la alusión a gobernanza regional. La búsqueda de diferenciación no ha perdido centralidad y la utilización de diferentes categorías (región, regionalismo, integración) como intercambiables opaca el debate.

El segundo momento de visibilización de las regiones como tema de moda se desarrolla en la década de 1990 como parte de la reconfiguración del orden económico y político internacional concomitante al proceso de globalización neoliberal. La construcción de regiones obtiene renovada popularidad como parte de las discusiones sobre la supuesta pérdida de centralidad de los estados en este nuevo orden -en detrimento de otros actores de actuación global con capacidad de incidencia y de organización transnacional-. Dos debates marcan la readecuación de los postulados de la integración: globalización versus regionalización, por un lado; multilateralismo versus regionalismo, por el otro. En el marco de este último, las experiencias históricas de construcción de regiones se resignifica a partir de la noción de olas de regionalismo, indicando como viejo/cerrado a los acuerdos regionales creados en la década de 1960 para diferenciarlos de los nuevos/abiertos que se encontraban en formación. La categoría integración es reemplazada por la de regionalismo.

A partir de entonces se bifurca el campo de estudios de la IR en dos líneas que se desarrollarán en paralelo y con escaso diálogo entre sí: las teorías de la integración europea -complejizando la cantidad y variedad de enfoques que buscan explicar diferentes aristas de este proceso- y el floreciente enfoque del nuevo regionalismo, que finalmente adoptó el nombre de Teoría del Nuevo Regionalismo ${ }^{17}$. Así, dos patrones de integración proporcionaron la base empírica para la construcción de la teoría. Las primeras avanzaron en el análisis del proceso multifacético de integración europea (como se expuso ut supra). Las segundas se desarrollaron bajo la preocupación de analizar la relación entre regionalización y globalización, delimitar el concepto de región y distinguir las progresiones de la construcción de región dado el mapa global de múltiples y diversos acuerdos. Sus referentes se inscriben en la economía política internacional y, de manera creciente, en el Constructivismo, generando collage de

\footnotetext{
17 En 1998 Björn Hettne y Fredriek Söderbaum publicaron un artículo seminal para conceptualizar el "fenómeno cualitativamente nuevo" del nuevo regionalismo y sistematizaron el debate proponiendo la noción de enfoque. Posteriormente, consideraron que había madurado en teoría. HETTNE, Björn y SÖDERBAUM, Fredrik, "The new regionalism approach" en Politeia, vol. 17, no 3, 1998; HETTNE, Björn y SÖDERBAUM, Fredrik, "Theorising the rise of regionness" en BRESLIN, Shaun, et. al. (eds.) New Regionalisms in the Global Political Economy. Theories and Cases, Routledge, Londres, 2002.
} 
perspectivas teóricas ${ }^{18}$.

Pese a la nominación de la teoría, varios de sus referentes comparten que la división viejo versus nuevo regionalismo resulta interesante sólo en términos analíticos, y reconocen la búsqueda de una visión de conjunto ${ }^{19}$. Esta cuestión es central porque desde el momento de agitación conceptual, en las redes centrales de producción de conocimiento se dejó de utilizar el calificativo de "nuevo" -especialmente tras el auge del regionalismo comparado-. Al centrarse en cómo las regiones se construyen, sostienen y transforman a lo largo del tiempo, se parte del supuesto de que la construcción de la región es un proceso continuo que se desarrolla de manera acumulativa -más no lineal-. Esta operación permite diferenciar categorías afines -región, regionalización, regionalismo ${ }^{20}$, regionidad ${ }^{21}-$ y colocar en un segundo plano, cuando no resignar, la noción de integración. Más allá de los matices, las teorías del Nuevo Regionalismo destaca aspectos relevantes para el estudio de las regiones: la construcción de la región como un proceso ascendente, el papel de los actores no estatales y la afirmación de que son construcciones sociales. Por lo tanto, las regiones se encuentran en tensión a partir de proyectos políticos que disputan sobre la definición de lo que la región representa. Así, las ideas e identidades, tanto como los intereses, juegan un papel significativo en la definición y creación de una región.

El tercer momento de apogeo del estudio de la integración en las RI es el actual y se explica a partir de dos cuestiones. Primero, desde el año 2010, la agitación conceptual intra campo a partir de la pérdida de dinamismo de la UE como parte de sus crisis junto con la gravitación de otras experiencias de construcción. En el marco de estas discusiones, la propuesta para superar los antagonismos y la falta de diálogo entre las Teorías de la Integración Europea y las Teorías del Nuevo Regionalismo enfatiza el desarrollo del Regionalismo Comparado. Segundo, de manera más reciente, como parte de las discusiones disciplinarias sobre el centrismo occidental en las RI y la demanda por incorporar abordajes desarrollados por académicos y académicas de lo que, tentativamente, llamaremos el Sur global, las regiones ganaron popularidad a partir de la afirmación de la existencia de las RI Globales y la valorización de los aportes locales en esa construcción.

Así, el desarrollo de las dos teorías centrales del campo de estudios avanzó por canales paralelos durante una década, reactualizando el señalamiento de Donald Puchala en 1971 sobre los hombres ciegos y la incapacidad para el diálogo ${ }^{22}$ : las teorías de la Integración

${ }^{18}$ SCHULZ, Michael; SÖDERBAUM, Fredrik y OJENDAL, Joakim, "Introduction: a framework for understanding regionalization" en SCHULZ, Michael; SÖDERBAUM, Fredrik, y OJENDAL, Joakim, (eds.) Regionalization in a Globalizing World: A Comparative Perspective on Forms, Actors, and Processes, Zed Books, Londres, 2001.

${ }^{19}$ FABBRI, Claudia, "The constructivist promise and regional integration: An answer to "old" and "new" puzzles. The South American case", Working Paper no 182, Department of Politics and International Studies, University of Warwick, 2005; WARLEIGH-LACK, Alex, "Towards a conceptual framework for regionalisation: bridging 'new regionalism' and 'integration theory'" en Review of International Political Economy, vol. 13, no 5, 2006, , pp. 750-771; FAWCETT, Louise, "Exploring regional domains: A comparative history of regionalism" en International Affairs, vol. 80, no 3, 2004.

${ }^{20}$ HURRELL, Andrew, "Regionalism in theoretical perspective" en Fawcett, Louise y HURRELL, Andrew, Regionalism in World Politics, Oxford University Press, Oxford, 1995, pp. 31-71.

${ }^{21}$ HETTNE, Björn y SÖDERBAUM, Fredrik, Theorising... op.cit.

22 PUCHALA, Donald J. "Of blind men, elephants and international integration" en JCMS: Journal of Common Market Studies, vol. 10, no 3, 1971, pp. 267-284. 
Europea porque prosiguieron sus análisis bajo el mito reconfortante de que la UE es una entidad suis generis mientras que desde las Teorías del Nuevo Regionalismo rechazaron los abordajes de los primeros por considerar que las variables dependientes son diferentes en uno y otro caso ${ }^{23}$. La necesidad de encuentro comienza a ser visibilizada en un canal de divulgación gravitante con la elaboración de un dossier que condensa las discusiones para tender puentes entre ambos corpus teóricos, conceptuales y metodológicos y avanza en la propuesta de una agenda de trabajo para el campo de estudios desde los estudios comparados ${ }^{24}$.

El Regionalismo Comparado venía desarrollándose como un sub-área de trabajo dentro del campo de estudios de la integración - desde el trabajo de los neofuncionalistas- y, tras este estímulo, se erigió como un programa de investigación ${ }^{25}$. Si bien ha avanzado y se considera una herramienta significativa para acercar las posiciones dentro del campo, aún cuenta con problemas en los aspectos ontológicos, teóricos y metodológicos ${ }^{26}$. Especialmente, las críticas resaltan que no existe un marco teórico y decisiones metodológicas compartidas ${ }^{27}$. No obstante, buena parte de los referentes del campo de estudios - tanto en la vertiente europea como la del (nuevo) regionalismo- han avanzado en caracterizaciones del programa y utilizado este herramental para el estudio de diferentes regiones. Un elemento significativo de la consolidación de esta línea ha sido la elaboración de un manual ${ }^{28}$, ya que este tipo de publicaciones - actualmente- da cuenta de la consagración de un campo.

De manera sucinta, al observar las últimas producciones académicas del campo, es posible afirmar que la agenda temática del regionalismo comparado ha estimulado el trabajo entre las dos escuelas (o paradigmas). Incluso -en casos puntuales- es dable argumentar que ha habido un proceso de socialización de los actores en estas redes de divulgación que ha nutrido el diálogo y acercamiento de posturas. A título ilustrativo, se puede señalar que autores que habían abordado el fenómeno de europeización, dieron paso a estudios de difusión de políticas en los regionalismos para organizar la agenda de investigación actual del regionalismo comparado ${ }^{29}$.

${ }^{23}$ WARLEIGH-LACK, Alex, y Luk VAN LANGENHOVE. "Rethinking EU studies: the contribution of comparative regionalism" en Journal of European Integration, vol. 32, no 6, 2010, pp. 541-562; SÖDERBAUM, Fredrik y SBRAGIA, Alberta, "EU studies and the 'new regionalism': what can be gained from dialogue?" en Journal of European Integration, vol. 32, n 6, 2010, pp. 563-582.

${ }^{24}$ Esta estrategia permite renovar las conceptualizaciones de los actuales esquemas de integración sin caer en las falacias de los casos individuales o considerar al regionalismo como un concepto atrapatodo. PERROTTA, Daniela, El Regionalismo... op.cit., p. 50.

25 SÖDERBAUM, Fredrik, "Consolidating comparative regionalism: from euro-centrism to global comparison", Paper for the GARNET 2008 Annual Conference, Sciences Po Bordeaux, 17 a 19 de septiembre de 2008; SBRAGIA, Alberta, "Comparative regionalism: what might it be?" en JCMS: Journal of Common Market Studies, vol. 46, no 1, 2008, pp. 29-49; DE LOMBAERDE, Philippe, "The good, the bad and the ugly in comparative regionalism: a comment on Sbragia" en JCMS: Journal of Common Market Studies, vol. 49, no 3, 2011, pp. 675-681; ACHARYA, Amitav, "Comparative regionalism: a field whose time has come?" en The International Spectator, vol. 47, n० 1, 2012, pp. 3-15.

${ }^{26}$ DE LOMBAERDE, Philippe, et al. "The problem of comparison in comparative regionalism" en Review of International Studies, vol. 36, no 3, 2010, pp. 731-753.

27 CLOSA, Carlos, "Mainstreaming regionalism" en EUI Working Paper 2015/12, 2015.

28 BÖRZEL, Tanja A. y RISSE, Thomas, The Oxford Handbook of Comparative Regionalism, Oxford University Press, Oxford, 2016.

${ }^{29}$ Es notable la adaptación de Börzel y Risse en este sentido: BÖRZEL, Tanja y RISSE, Thomas, When Europe Hits Home: Europeization and Domestic Change, Instituto Universitario Europeo, Florencia, 2000; BÖRZEL, Tanja y RISSE, Thomas, "From Europeanisation to diffusion: introduction" en West European Politics vol. 35, no 1, 2011, pp. 1-19; BÖRZEL, Tanja y RISSE, Thomas, When... op.cit; BÖRZEL, Tanja A., y Thomas RISSE. "From 
En otro orden, desde posturas críticas se señala que los problemas del Regionalismo Comparado pueden sortearse desde la perspectiva del regionalismo regulatorio. Este enfoque abreva de la Ciencia Política y busca saldar la cuestión de diseños institucionales disímiles para colocar el foco en la puesta en marcha de políticas públicas regionales y su vinculación con la política doméstica ${ }^{30}$. No obstante, la propuesta no ha obtenido popularidad en el centro del campo, quedando en una posición residual, pese a su versatilidad para asir experiencias regionales con variados diseños institucionales (en el marco de formas de gobierno nacional variadas).

Por último, el corolario de la discusión intra-campo es que la categoría indiscutida para referenciar estos fenómenos es la de regionalismo, mientras integración se reserva para la excepcionalidad europea. De aquí se desprende un desafío a la construcción de conocimiento en América Latina ya que las formulaciones generadas para aprehender el período que se abre con el siglo XXI han tenido -mayoritariamente- la tendencia a calificar el tipo de regionalismo más que a discernir cómo es el proceso de construcción de región, sus proyectos y resultados - asumiendo que el objeto de estudio es uno en constante movimiento-.

\section{Las redes periféricas: la teoría social latinoamericana y su aporte al estudio de la integración}

El desarrollo del campo de estudios que presentamos ha marcado el abordaje de la integración en América Latina, especialmente en cuanto a referenciar el caso europeo, primero, y a periodizarlo en términos de olas, luego ${ }^{31}$. En efecto, las teorías de la red de conocimiento central también abordaron esta región: primeramente, el propio Haas se interesó en aplicar sus postulados neofuncionalistas al Mercado Común Centroamericano y contó con la asistencia de Philippe Schmitter - tal como recupera Andrés Malamud ${ }^{32}-$. Al hacerlo, alertó que sus constructos no eran fácilmente trasladables ya que cada región desarrolla sus propios objetivos funcionales y estímulos integracionistas ${ }^{33}$. Schmitter y Malamud son referencias gravitantes para la aplicación del herramental de las Teorías de la Integración Europea al estudio de los casos latinoamericanos para explicar lo que se define como limitaciones de estas experiencias (el fuerte sesgo del presidencialismo, la gradualidad en la cesión de soberanía -que los llevan a indicar que no se trata de integración- y, de manera más reciente, el solapamiento de acuerdos) ${ }^{34}$. Por su parte, también desde las Teorías del Nuevo Regionalismo se abordaron

the Euro to the Schengen Crises: European Integration Theories, Politicization, and Identity Politics" en Journal of European Public Policy, vol. 25, n 1, 2018, pp. 83-108.

30 HAMERI, Shahar, "Beyond methodological nationalism, but whereto for the study of regional governance?" en Journal of International Affairs, vol. 63, no 3, 2009, pp. 430-441; HAMERI, Shahar y JAYASURIYA, Kanishka, "Regulatory regionalism and the dynamics of territorial politics: the case of the Asia-Pacific region" en Political Studies, vol. 59, no 1, 2011, pp. 20-37.

${ }^{31}$ DABÈNE, Olivier, The Politics of Regional Integration in Latin America: Theoretical and Comparative Explorations, Palgrave Macmillan, 2009; DABĖNE, Olivier, "Explaining Latin America's fourth wave of regionalism. Regional integration of a third kind," Latin American Studies Association San Francisco, 2012; SÖDERBAUM, Fredrik, Rethinking Regionalism, Rethinking World Politics, Palgrave, 2016; BID, El nuevo... op.cit; MANSFIELD, Edward D. y MILNER, Helen V., "The new wave of regionalism" en International organization 53.3, 1999; FAWCETT, Louise y HURRELL, Andrew, Regionalism in world politics regional organization and international order New York: Oxford University Press, 1995.

32 MALAMUD, Andrés, "Latin American regionalism and eu studies" en Journal of European Integration 32.6, 2010.

33 HAAS, Ernst, "International integration: The european and the universal process," en International organization $15.03,1961$.

34 MALAMUD, Andrés, "Presidential diplomacy and the institutional underpinnings of mercosur: An empirical examination," en Latin American Research Review 40.1, 2005, MALAMUD, Andrés y SCHMITTER, Philippe, "La 
los acuerdos regionales de América Latina, destacando un sesgo desde la economía política internacional para comprenderlo en la primera formulación del nuevo regionalismo, vinculado al proceso de reforma estructural de los estados ${ }^{35}$. No obstante este acompañamiento de las tendencias generales, la región ha generado un corpus propio de conocimiento para abordar sus peculiaridades. Una diferencia sustantiva es el marco disciplinar: estas explicaciones no fueron desarrolladas por académicos de RI, sino que por intelectuales que desde otras disciplinas sociales (sociología, economía, derecho internacional, ciencia política) abordaron problemas en clave regional.

La unidad latinoamericana ha sido abordada por movimientos políticos, intelectuales y artísticos desde las guerras de independencia y existe un consenso visibilizado recientemente que lo relaciona con dos metas políticas a alcanzar: la autonomía y el desarrollo. La alusión a ambas como pulsiones integracionistas -es decir, como fuerzas que impulsan a los sujetos a poner en marcha una acción, según la acepción psicoanalítica freudiana de vocablo- fue desarrollada por José Paradiso ${ }^{36}$. Desde aquí, se acepta la tesis latinoamericana de comprender a la integración como un instrumento de política. El mapeo de este recorrido conceptual a lo largo de las experiencias históricas de regionalismo fue realizado por varios autores desde entonces, generando una nueva y pujante línea de trabajo ${ }^{37}$. Con la recuperación y visibilización de los aportes latinoamericanos y latinoamericanistas se afirma un pensamiento latinoamericano para la integración entendido como el conjunto de ideas sistematizadas sobre los procesos de construcción de región, unionismo e integración y las dimensiones asociadas a éstos en América Latina, cualesquiera fueran los límites difusos que esta arena política representa ${ }^{38}$. Los tres grandes problemas sobre los cuales se estructura este PLI a lo largo del

experiencia de integración europea y el potencial de integración del mercosur," en Desarrollo Económico 46.181, 2006, MALAMUD, Andrés, "Overlapping regionalism, no integration: Conceptual issues and the latin american experiences," en, 2013.

35 PHILLIPS, Nicola, "Regionalist governance in the new political economy of development:"Relaunching" the mercosur," en Third World Quarterly 22.4, 2001, GÓMEZ MERA, Laura, "Explaining mercosur's survival : Strategic sources of argentine-brazilian convergence," en Journal of Latin American Studies 37, 2005, GÓMEZMERA, Laura y MOLINARI, Andrea, "Overlapping institutions, learning, and dispute initiation in regional trade agreements: Evidence from south america," en International Studies Quarterly 58.2, 2014, TUSSIE, Diana y TRUCCO, Pablo, Nación y región en américa del sur: Los actores nacionales y la economía política de la integración sudamericana Buenos Aires: Teseo, 2010, QUILICONI, Cintia, "Atlántico versus pacífico: Las alternativas en competencia de la integración comercial en américa latina," en Relaciones Internacionales.47, 2014, QUILICONI, Cintia, "Competitive diffusion of trade agreements in latin america," en International Studies Review 15.2, 2014, CARRANZA, Mario E, "Can mercosur survive? Domestic and international constraints on mercosur," en Latin American Politics and Society 45.2, 2003, CARRANZA, Mario E, "Resilient or declining? Latin american regional economic blocs in the postneoliberal era," en Latin American Politics and Society 56.3, 2014. BIANCULLI, Andrea C y HOFFMANN, Andrea Ribeiro, Regional organizations and social policy in europe and latin america: A space for social citizenship? Springer, 2016, BOUZAS, Roberto, "El mercosur diez años después. ¿proceso de aprendizaje o deja vu?," en Desarrollo Económico 41.162, 2001.

36 Lamentablemente, estas ideas fueron desarrolladas en diferentes conferencias desde el año 2010 y la obra que las reúne ("El ideal unificador en América Latina. Economía, sociedad y política en los procesos de integración") aún se encuentra en prensa. Entrevista con el autor, 2012.

37 BRICEÑO RUIZ, José, RIVAROLA PUNTIGLIANO, Andrés y CASAS GRAGEA, Ángel, Integración latinoamericana y caribeña. Política y economía. Madrid: Fondo de Cultura Económica, 2012. BERNAL-MEZA, Raúl. "El Regionalismo: Conceptos, Paradigmas Y Procesos En El Sistema Mundial Contemporáneo." Aportes para la Integración Latinoamericana Año XV, Nro. 21, 2009. BRICEÑO RUIZ, José, y Alejandro SIMONOFF. Integración Y Cooperación Regional En América Latina: Una Relectura a Partir De La Teoría De La Autonomía. Buenos Aires: Editorial Biblos, 2015. MÍGUEZ, María Cecilia. "La Autonomía Heterodoxa Y La Clasificación De Las Políticas Exteriores En La Argentina." Revista de relaciones internacionales, estrategia y seguridad 122 (2017): 207-229. BIALAKOWSKY, Alberto, Marcelo ARNOLD-CATHALIFAUD, y Paulo Henrique MARTINS. El Pensamiento Latinoamericano: Diálogos En Alas. Sociedad Y Sociología. Buenos Aires: ALAS. CLACSO. Teseo, 2015

38 PAIKIN, Damián, PERROTTA, Daniela y PORCELLI, Emanuel, "Pensamiento latinoamericano para la integración," en Crítica y Emancipación Año VIII.15, 2016. 
tiempo son la autonomía, el desarrollo y la defensa de los recursos naturales.

Excede los objetivos del trabajo revisitar el robusto aporte del pensamiento latinoamericano para la integración (desde fines del siglo XIX a nuestros días), por un lado, y la aplicación de las teorías de la integración regional y el regionalismo centrales a esta región, por otro. Así como dar cuenta in extenso del incremento de la producción de conocimiento sobre integración desde los años 2008-2010. Por lo tanto, el recorte seleccionado son las escuelas de pensamiento que abordaron la región desde mediados del siglo XX. Es menester destacar que el desarrollo de estas escuelas no coincide estrictamente con las experiencias históricas de regionalismo por la cuestión central de que el objetivo de éstas no es la construcción de región sino los tres problemas señalados. Ilustra este desfasaje que los primeros acuerdos de integración fueron creados a posteriori de su teorización -resultantes de las recomendaciones de política surgidas en las redes de conocimiento de entonces-. En el caso de la etapa más reciente del campo de estudios, efectivamente, la producción de conocimiento sobre integración en el Siglo XXI ha estado fuertemente estimulada a partir de los acuerdos creados y reconfigurados en este momento $-\mathrm{y}$, conforme se observa más adelante, a partir de la creación de la Unión de Naciones Suramericanas (UNASUR)—.

La producción de conocimiento sobre integración fue desarrollada y refinada en organizaciones y redes académicas regionales. Estas redes tuvieron sus epicentros en Santiago de Chile, Buenos Aires, San Pablo, Caracas y Ciudad de México, reproduciendo las asimetrías intra-regionales de los complejos científicos, tecnológicos y universitarios ${ }^{39}$. De las instituciones regionales creadas destacamos: la Comisión Económica para América Latina (CEPAL, 1948), la Facultad Latinoamericana de Ciencias Sociales (FLACSO, 1957), el Instituto para la Integración de América Latina (INTAL, 1965), el Consejo Latinoamericano de Ciencias Sociales (CLACSO, 1967) y el Sistema Económico Latinoamericano y del Caribe (SELA, 1975). Por ellas transitaron los referentes del pensamiento social latinoamericano, muchos vinculados a la actividad política profesional, como funcionarios o asesores. En este punto, es menester destacar dos cuestiones. Primero, los referentes a los que aludimos fueron mayoritariamente hombres. Segundo, en el recorte seleccionado se ha dejado de lado la incorporación de Centroamérica y del Caribe, espacios que tuvieron desarrollos gravitantes, en redes académicas con carácter aún más periférico ${ }^{40}$.

A modo de aclaración, es posible realizar un seguimiento de estas redes académicas y la producción de conocimiento sobre integración regional a partir de los espacios de

${ }^{39}$ BEIGEL, Fernanda, Autonomía y dependencia académica. Universidad e investigación científica en un circuito periférico: Chile y argentina (1950-1980), Investigaciones y ensayos Buenos Aires: Biblos, 2010, BEIGEL, Fernanda, "La flacso chilena y la regionalización de las ciencias sociales en américa latina (1957-1973)," en Revista mexicana de sociología 71.2, 2009, BEIGEL, Fernanda, "Chile: Un centro periférico para la internacionalización de las ciencias sociales latinoamericanas y la construcción de un prestigio académico regional (1953-1973)," en Revista de la Red Intercátedras de Historia de América Latina Contemporánea-Segunda Época.1, 2014.

${ }^{40} \mathrm{La}$ red regional que destaca fue el Consejo Superior Centroamericano (CSUCA) y, con el advenimiento de las dictaduras en el Cono Sur, la apertura de nuevas FLACSO en estos países. El exilio y las diásporas permitieron ampliar las redes regionales. También con la Revolución Cubana se gestó una nutrida red política-artísticaintelectual de pensamiento social latinoamericano. Entre los autores que pensaron desde los años sesenta la región desde la peculiaridad del Caribe destacan Frantz Fanón Norman Girvan, Sylvia Winter, Aimé Césaire, Lloyd A. Best y Kari Polanyi Levitt, entre otros. VALDÉS GARCÍA, Félix, Antología del pensamiento crítico caribeño contemporáneo. West indies, antillas francesas y antillas holandesas Buenos Aires: CLACSO, 2017. 
reflexión y publicación gravitantes en los diferentes momentos que señalamos ${ }^{41}$. Se destacan por estos años iniciales el rol que tuvo la revista Desarrollo Económico fundada en 1960; Estudios Internacionales, de 1967; Nueva Sociedad (NUSO), creada en 1972; las publicaciones de la CEPAL y el INTAl; así como el Centro Editor de América Latina (CEAL), de 1966. Destaca especialmente, la creación del Programa de Estudios Conjuntos sobre las Relaciones Internacionales de América Latina (RIAL) estimulada por Luciano Tomassini ${ }^{42}$. No profundizamos aquí en cada uno de estos circuitos, si bien forma parte de la investigación grupal en curso.

La Teoría Social Latinoamericana ${ }^{43}$ fue desarrollada en el marco de estos espacios de intercambio regional, generando escuelas propias de pensamiento que abordaron la IR y consolidaron un campo de estudios específico, vigente y en movimiento a nuestros días ${ }^{44}$. Las tres escuelas con efectos sobre el estudio de la IR -actualmente popularizadas- son: el estructuralismo económico latinoamericano, la(s) teoría(s) de la dependencia y la escuela autonomista en política exterior. A éstas se adiciona una cuarta, proveniente de las ciencias exactas y naturales: la escuela latinoamericana en ciencia, tecnología y desarrollo ${ }^{45}$ (véase Tabla 1) Otra característica fue la circulación y participación simultánea de estos referentes en más de un circuito. A título ilustrativo, Hélio Jaguaribe participaba de la discusión entre los economistas en $\mathrm{CLACSO}^{46}$ mientras sus aportes al rol de la ciencia en países periféricos robustecían la escuela autonomista ${ }^{47}$. Es posible indicar que estos referentes intelectuales tenían un amplio conocimiento de las ciencias sociales y podían pivotear entre disciplinas, de allí su interés y aporte a los estudios internacionales. Adicionalmente, se encontraban comprometidos con el avance riguroso de la producción de conocimiento en base a objetivos políticos de mejora general del bienestar en la región; lo que incluía una concepción peculiar sobre la utilidad social de la ciencia. De allí sus múltiples sombreros: académicos, intelectuales, practicantes de la política como profesión.

${ }^{41}$ Esta propuesta metodológica para analizar el campo de estudios de la integración regional en América Latina entre los años cincuenta y noventa fue presentada en el trabajo: PERROTTA, Daniela, "La Integración Regional En América Del Sur Como Objeto De Estudio: ¿En Pos De la Construcción De Un Campo?" III Jornadas de Relaciones Internacionales (2012), retomando el proyecto de investigación del autor "La construcción del "campo de estudio" sobre la integración regional en América Latina: pasado y presente, rupturas y continuidades, dependencia y autonomía" (CLACSO, 2012).

42 TOMASSINI, Luciano. "Los Estudios Internacionales En América Latina: Algunas Contribuciones." Estudios internacionales 1352 (1980): 545-552.

${ }^{43}$ Se opta por el singular para nombrar este corpus, si bien son múltiples teorías de lo social desde las variadas disciplinas de las ciencias sociales y las humanidades.

${ }^{44}$ Actualmente, estamos desarrollando una investigación sobre los primeros veinte años de CLACSO y las discusiones teóricas y metodológicas del circuito de intelectuales que transitaron por este espacio institucional respecto de la integración regional.

45 DAGNINO, Renato, THOMAS, Hernán y DAVYT, Amílcar, "El pensamiento en ciencia, tecnología y sociedad en latinoamérica: Una interpretación política de su trayectoria," en Redes III.7, 1996. SÁBATO, Jorge A., El pensamiento latinoamericano en la problemática ciencia - tecnología - desarrollo - dependencia Buenos Aires: MINCYT - Biblioteca Nacional, 2011.

${ }^{46}$ El primer secretario ejecutivo de CLACSO fue Aldo Ferrer y en el marco de la realización de la primera Asamblea General (Lima) en 1968 se discutió la dependencia político-económica de la región, abordando la construcción del modelo latinoamericano de integración. El debate fue organizado a partir de la presentación de los robustos trabajos elaborados por Helio Jaguaribe, Aldo Ferrer, Miguel S. Wionczek y Theotonio Dos Santos.

47 JAGUARIBE, Helio, Desarrollo económico y desarrollo político Buenos Aires: EUDEBA, 1968, JAGUARIBE, Helio, "Autonomía periférica y hegemonía céntrica," en Estudios internacionales 12.46, 1979. 
Tabla 1. Escuelas de pensamiento social latinoamericano y aportes al estudio de la integración (1960-1990)

\begin{tabular}{|c|c|c|}
\hline Escuela & Ideas centrales & Autores \\
\hline $\begin{array}{l}\text { Estructuralismo } \\
\text { económico }\end{array}$ & $\begin{array}{l}\text { Las características estructurales de la } \\
\text { región y la inserción internacional que } \\
\text { deteriora progresivamente los términos } \\
\text { del intercambio han de ser corregidos por } \\
\text { medio de la generación de un desarrollo } \\
\text { industrial propio a partir de la construcción } \\
\text { de un mercado regional unificado y de una } \\
\text { estructura asociativa en términos de cadenas } \\
\text { de valor. } \\
\text { La integración regional es clave para la } \\
\text { conformación del mercado ampliado que } \\
\text { requiere el proceso de industrialización para } \\
\text { pasar de un modelo liviano a uno pesado. } \\
\text { Incorporación del "mito de la integración" } \\
\text { (Herrera) para nutrir las herramientas } \\
\text { de construcción de un mercado regional } \\
\text { planificado con un pensamiento filosófico- } \\
\text { político capaz de brindarle un sentido global. } \\
\text { Diferenciación entre densidad nacional y } \\
\text { densidad regional (Ferrer). }\end{array}$ & \begin{tabular}{|l} 
Raúl Prebisch \\
Celso Furtado \\
Aldo Ferrer \\
Felipe Herrera \\
Helio Jaguaribe \\
Osvaldo Sunkel
\end{tabular} \\
\hline Dependencia & $\begin{array}{l}\text { La dependencia es una relación } \\
\text { condicionante: los países dominantes pueden } \\
\text { expandirse y auto-impulsarse en tanto que } \\
\text { otros (dependientes) solamente pueden } \\
\text { hacerlo como reflejo de tal expansión; } \\
\text { quedan así situados en el retraso y bajo la } \\
\text { explotación de los dominados, condicionados } \\
\text { en su estructura interna en función de los } \\
\text { intereses hegemónicos. } \\
\text { La dependencia no se supera aislando } \\
\text { al país, sino cambiando las estructuras } \\
\text { internas, lo que conduce al enfrentamiento } \\
\text { con esa estructura internacional. } \\
\text { Esta condición interna e integral de la } \\
\text { sociedad latinoamericana determina a las } \\
\text { burguesías dominantes, que son conscientes } \\
\text { de tal condición y la aceptan gustosa. }\end{array}$ & $\begin{array}{l}\text { Theotonio Dos Santos } \\
\text { Fernando Henrique Cardoso } \\
\text { Enzo Faletto } \\
\text { André Gunder Frank } \\
\text { Ruy Mauro Marini } \\
\text { Vânia Bambirra }\end{array}$ \\
\hline
\end{tabular}




\begin{tabular}{|c|c|c|}
\hline Autonomía & $\begin{array}{l}\text { Definir la ubicación y las posibilidades del } \\
\text { establecimiento de objetivos y políticas } \\
\text { exteriores autónomas respecto de los centros } \\
\text { de poder. } \\
\text { Caracterizar el sistema internacional y } \\
\text { la distribución asimétrica del poder a su } \\
\text { interior. } \\
\text { Comprender el rol de los factores domésticos } \\
\text {-ya sea en términos de subsistemas } \\
\text { (Jaguaribe) o de los actores que definen o } \\
\text { inciden sobre la política exterior (Puig)-. }\end{array}$ & $\begin{array}{l}\text { Juan Carlos Puig } \\
\text { Helio Jaguaribe } \\
\text { Luciano Tomassini } \\
\text { Guillermo Figari } \\
\text { Tullo Vigevani } \\
\text { Maria Regina Soares de Lima }\end{array}$ \\
\hline $\begin{array}{l}\text { Latinoamericana en } \\
\text { Ciencia, Tecnología } \\
\text { y Desarrollo }\end{array}$ & $\begin{array}{l}\text { Establecer una propuesta de desarrollo } \\
\text { tecnológico propio -latinoamericano- a } \\
\text { partir de la inserción de políticas sectoriales } \\
\text { y nacionales como variable fundamental del } \\
\text { desarrollo económico y social integral. } \\
\text { Discusión sobre la forma y la finalidad } \\
\text { de hacer ciencia en la región: utilizando } \\
\text { metodologías y teorías propias o foráneas y } \\
\text { en vinculación o no con el cambio social. } \\
\text { Búsqueda de autonomía científica y } \\
\text { tecnológica. Diferenciación entre cientificismo } \\
\text { y ciencia politizada (Varsavsky). }\end{array}$ & $\begin{array}{l}\text { Jorge Sábato } \\
\text { Amílcar Herrera } \\
\text { Oscar Varsavsky } \\
\text { Sara Rietti } \\
\text { José Leite Lopes } \\
\text { Miguel Wionczek } \\
\text { Francisco Sagasti } \\
\text { Máximo Halty } \\
\text { Marcel Roche } \\
\text { Helio Jaguaribe } \\
\text { Osvaldo Sunkel }\end{array}$ \\
\hline
\end{tabular}

Fuente: elaboración propia. Cada Escuela tiene sus continuadore/as a la fecha.

Las tres primeras escuelas se han mantenido a lo largo de los años a partir de la actualización de sus postulados por sus referentes y discípulos, así como también se han realizado relecturas y apropiaciones. Los avances que se registran en la producción de conocimiento autonómico en América Latina desde finales de los ochenta se encuentran en redes más fragmentadas y con menor visibilización, si bien es posible identificar un conjunto de referentes que transitan por redes académicas consolidadas a lo largo del tiempo. Como argumentamos, estas escuelas fueron creadas para analizar problemas generales de la región latinoamericana y caribeña; no obstante, al realizar el seguimiento por sus autores y discípulos se observa que hacia los ochenta comienza a ser objeto de indagación la integración, especialmente a raíz de las limitaciones de la Asociación Latinoamericana de Libre Comercio (ALALC) y de su transformación en Asociación Latinoamericana de Integración (ALADI). El auge de la globalización en los noventa y el momento unipolar - con la potencia hegemónica "en casa" - fueron estímulos insoslayables para pensar las regiones. Por citar dos ejemplos: en el campo económico, los escritos de Aldo Ferrer para construir un esquema de integración desde el MERCOSUR frente al auge de la globalización neoliberal y la distinción entre densidad nacional y densidad regional ${ }^{48}$. La discusión de Juan Carlos Puig de 1989 sobre las dificultades que evidenció la ALALC le permite formular el tipo de integración -la solidaria- que se ajusta a fines autonomistas ${ }^{49}$.

\footnotetext{
48 FERRER, Aldo, Hechos y ficciones de la globalización: Argentina y el mercosur en el sistema internacional Buenos Aires: Fondo de cultura económica, 1997, FERRER, Aldo, "Densidad nacional y densidad regional," en Revista Densidades.1, 2008.

49 PUIG, Juan Carlos, "Integración y autonomía en américa latina en las postrimerías del siglo XX," en Integración Latinoamericana enero-febrero, 1989.
} 
El renovado ímpetu a la construcción de regiones en el siglo XXI contribuyó al de las producciones sobre regionalismo. El movimiento del "regionalismo con adjetivos"50 postliberal ${ }^{51}$, posthegemónico ${ }^{52}$, inclusivo o social ${ }^{53}$, nuevo regionalismo estratégico ${ }^{54}-$ profundizó las características especiales de la construcción de región en esta parte del globo, más recurrió en el problema del caso único $(N=1)^{55}$. Entonces, si bien se avanzó en la generación de conocimiento -y el proceso quedó a medio camino dado el cambio de ciclo político y económico desde el 2012- también se profundizó la confusión conceptual con la utilización de categorías del circuito central para ganar visibilidad y reconocimiento en éste. Efectivamente, el gráfico 1 da cuenta del desarrollo de las publicaciones sobre el regionalismo latinoamericano en la Base de datos SCOPUS de la Compañía Elsevier ${ }^{56}$, es decir, en el espacio central de publicación y donde la academia de la región se encuentra sub-representada.

\section{Gráfico 1. Serie de Publicaciones en SCOPUS sobre regionalismo latinoamericano}

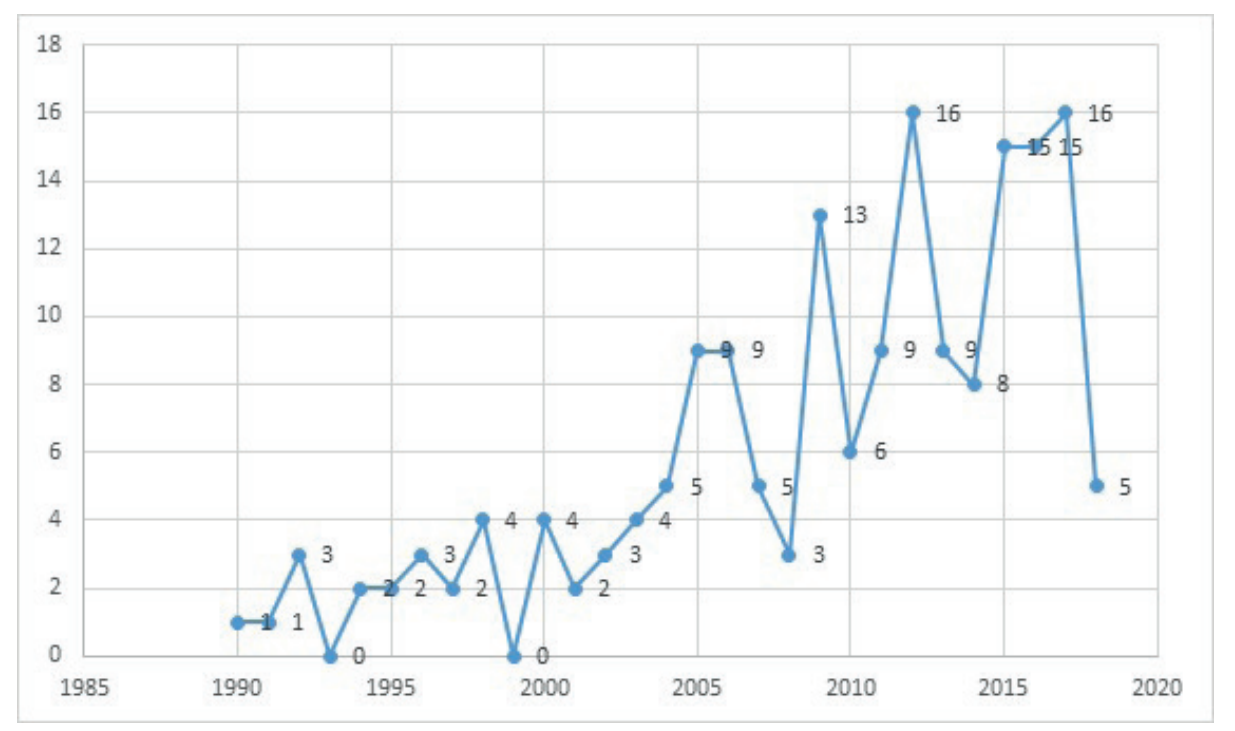

Fuente: elaboración propia en Scopus. Los términos que se usaron fueron "regionalismo latinoamericano" or "regionalism" and "Latin America". Fecha de Búsqueda: 09/06/2018.

50 PERROTTA, Daniela y PORCELLI, Emanuel, "'Regionalismo adjetivado": Desafíos teóricos para la comprensión de los procesos de construcción de región en américa latina," Documento de Trabajo Buenos Aires: CEAP, 2016.

${ }^{51}$ SANAHUJA, José Antonio, "Del 'regionalismo abierto' al 'regionalismo post liberal'. Crisis y cambio en la integración en américa latina y el caribe.," Anuario de la integración regional de américa latina y el gran caribe 20082009, eds. L MARTÍNEZ, L PEÑA y Mariana VAZQUEZ Buenos Aires: Coordinadora Regional de Investigaciones Económicas y Sociales-CRIES, 2008, SANAHUJA, José Antonio, "Post-liberal regionalism in south america: The case of unasur," en RSCAS Working Papers 5, 2012. MOTTA VEIGA, Pedro da y RÍOS, Sandra, O regionalismo pós-liberal, na américa do sul: Origens, iniciativas e dilemas (Santiago de Chile: CEPAL, 2007).

52 RIGGIROZZI, Pia y TUSSIE, Diana, "The rise of post-hegemonic regionalism in latin america," The rise of posthegemonic regionalism. The case of latin america, eds. Pia RIGGIROZZI y Diana TUSSIE, vol. 4 Dordrecht: Springer, 2012, RIGGIROZZI, Pía y GRUGEL, Jean, "Regional governance and legitimacy in south america: The meaning of unasur," en International Affairs 91.4, 2015, BRICEÑO RUIZ, José, "Ejes y modelos en la etapa actual de la integración económica regional en américa latina," en Estudios internacionales (Santiago) 45.175, 2013.

${ }^{53}$ VAZQUEZ, Mariana, "El mercosur social. Cambio político y nueva identidad para el proceso de integración regional en américa del sur," Mercosur 20 años, ed. Gerardo CAETANO Montevideo: Centro de Formación para la Integración Regional - CEFIR, 2011, BRICEÑO RUIZ, José, "Del regionalismo estratégico al regionalismo social y productivo. Las transformaciones del modelo de integración en el mercosur," El mercosur y las complejidades de la integración regional, ed. José BRICEÑO RUIZ Buenos Aires: TESEO, 2011.

${ }^{54}$ APONTE GARCÍA, Maribel, El nuevo regionalismo estratégico. Los primeros diez años del alba-tcp Buenos Aires: Consejo Latinoamericano de Ciencias Sociales - CLACSO, 2014, APONTE GARCÍA, Maribel y AMÉZQUITA PUNTIEL, Gloria, El alba-tcp. Origen y fruto del nuevo regionalismo latinoamericano y caribeño Buenos Aires: Concejo Latinoamericano de Ciencias Sociales (CLACSO), 2015.

55 PERROTTA, Daniela, El regionalismo...op.cit.

${ }^{56}$ Plataforma de búsqueda https://datasearch.elsevier.com/\#/search 
Entre 1990 y el 2018 se publicaron en Scopus 174 artículos que identifican como la primer palabra clave en sus trabajos "regionalismo latinoamericano". Se observa pues que existe una correlación entre el estudio del regionalismo y los procesos de construcción de región en América Latina. Los picos de publicación fueron los años 2017 y 2012, con 16 trabajos cada uno; seguidos por los años 2016 y 2015, con 15 trabajos cada uno; y el año 2009 con 13 artículos totales. Respecto de la procedencia de los y las autoras, el 27\% de esas publicaciones fueron realizadas en Estados Unidos (47 trabajos), seguido por Reino Unido en un 20\% (35 trabajos) y de nacionalidad indefinida un $12 \%$. El cuarto lugar lo ocupa Argentina con el 5,7\% (10 trabajos), seguida por México con el 5,2\% (9 artículos) y Brasil con 4,6\% (8 trabajos). Por supuesto, estos valores por "origen" del autor tiene el sesgo de ser una base donde no se encuentran representados mayoritariamente los y las académicas latinoamericanos. Buena parte de quienes publican en estas revistas son autores vinculados a la red central de producción de conocimiento por estar radicado en esas instituciones o haber realizado sus estudios de posgrado allí.

Al concentrarnos en las publicaciones realizadas en los dos repositorios más importantes y rigurosos de América Latina -Scielo (gráfico 2) y Redalyc (gráfico 3)-, es posible observar cuáles son las temáticas vinculadas al estudio del regionalismo.

\section{Gráfico 2. Red de Conceptos sobre Regionalismo en Publicaciones en la base SCIELO}

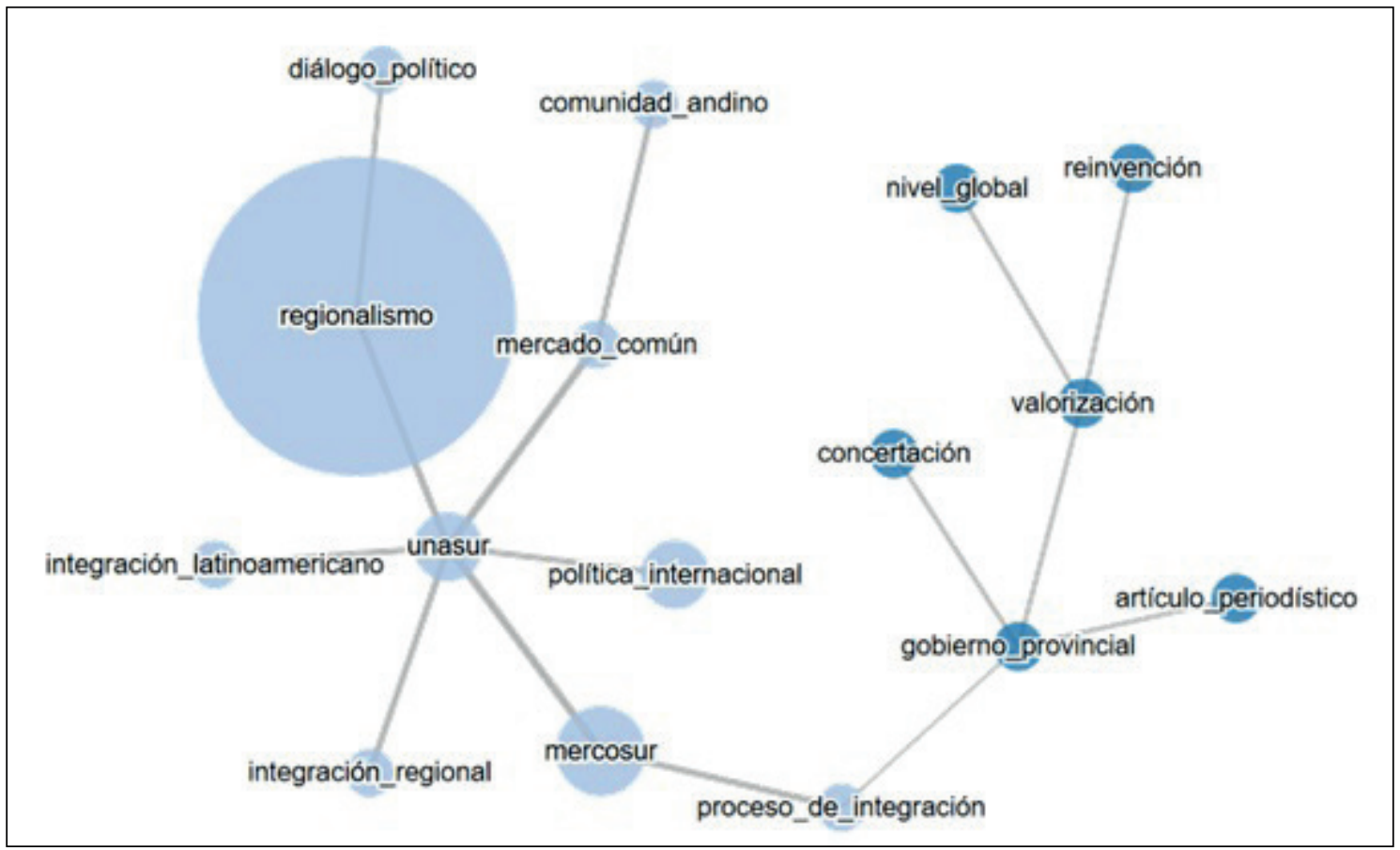

Fuente: elaboración propia en el portal Intelligo. Fecha de búsqueda: 09/06/2018. Criterio de búsqueda "Regionalismo" base de datos "Scielo.org" 


\section{Gráfico 3. Red de Conceptos sobre Regionalismo en Publicaciones en la base REDALyC}

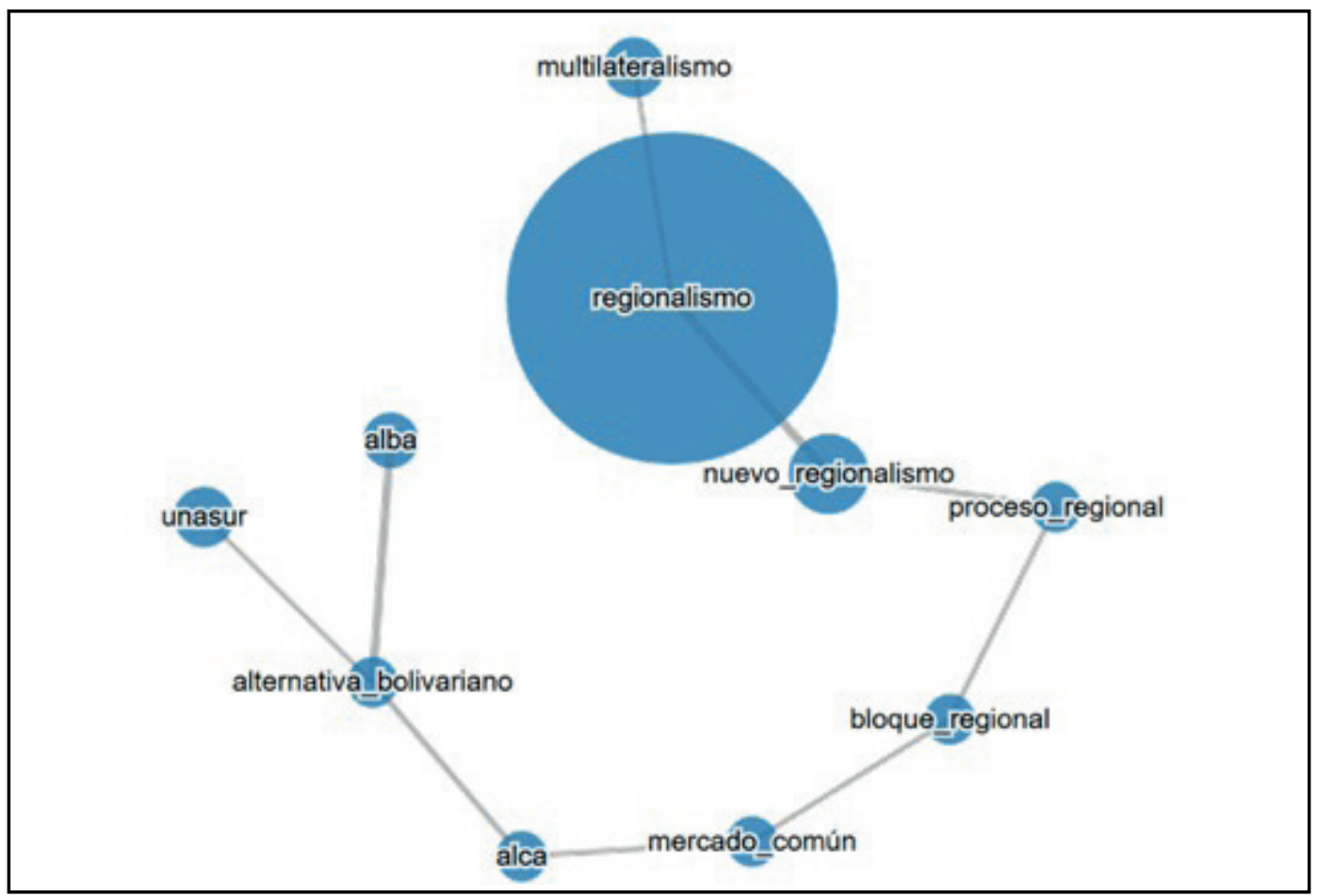

Fuente: elaboración propia en el portal Intelligo. Fecha de búsqueda: 09/06/2018. Criterio de búsqueda "Regionalismo" base de datos "Redalyc"

Estos dos gráficos son una red de conceptos que muestra en tamaño (distribución de frecuencias) aquellas categorías más frecuentemente vinculadas a la palabra clave que hemos definido -en este caso, "regionalismo"-. Igualmente, estos dos repositorios, si bien son más representativos de la academia local, no contemplan publicaciones gravitantes porque no se encuentran en ninguno de éstos. A título ilustrativo, el anuario de la integración regional latinoamericana y caribeña desarrollado por la Coordinadora Regional de Investigaciones Económicas y Sociales (CRIES), así como la revista Nueva Sociedad y otras de organismos regionales, no están allí contemplados.

De los tres gráficos es posible ejercitar una interesante hipótesis de trabajo para seguir problematizando: el campo de integración regional responde o reacciona ex-post a "la" política en América Latina. Retomando el Gráfico 1, los momentos en los que nuestro tema de búsqueda es más frecuente en la dinámica interanual de publicaciones expuesta en la serie se corresponden ex-post a hitos o acciones específicas de las instituciones (la crisis económica de los regionalismos de fin de siglo; los relanzamientos durante el primer lustro; la creación de la UNASUR y la gravitación que tuvo la construcción de políticas regionales en áreas "disruptivas" o "novedosas" como la defensa, la infraestructura, políticas sociales -especialmente salud- y democracia). Veamos esto más en detalle: si la discusión respecto de la cuestión regional no se evidencia en impacto en la distribución de frecuencias de las publicaciones más destacadas del campo de conocimientos no es demasiado arriesgado afirmar que el movimiento de la cuestión cognitiva en materia de integración regional no seguiría la dinámica bottoms-up (desde el campo científico hacia la política) sino su opuesto: desde la política hacia el campo científico. Por cierto, el despliegue teórico-metodológico necesario para la contrastación de 
esa hipótesis requiere de un trabajo empírico más complejo en dimensión y que escapa a los objetivos de este trabajo. En cualquier caso y con el espíritu de provocar al lector respecto de estas dinámicas, se pretende incentivar la discusión respecto de la relación entre política y conocimiento, propio de este campo de estudios, y su dinámica. Si se asume que nuestro campo de estudios ve gran parte de su desarrollo gracias a su capacidad de ofrecerse como una voz experta: ¿Por qué la voz experta no se materializa en la discusión del campo ex-ante a la práctica de las instituciones? ¿Qué voz experta está siendo un recurso cognitivo para las instituciones y por qué ese insumo no se plasma en las publicaciones más destacadas de ese campo académico?

En ningún caso se pretende aquí afirmar sin miramientos una posición que refuerce la tan criticada lógica de la "torre de marfil" de la academia. Es propósito de este simple ejercicio evidenciar la cuestión ensayando posibles modelos de indagación para nuestra hipótesis en, digamos, dos niveles: la ciencia de excelencia para los fenómenos políticos descritos no es el principal insumo de los policy-makers locales (en sentido amplio), y/o la ciencia de excelencia asumida en los regímenes de publicación de mayor impacto del globo no representa a la voz experta, cuya presencia en la academia no se refleja en esas dinámicas.

Efectivamente, sobre el primer punto, existe una profusa literatura sobre la vinculación entre conocimiento y política que da cuenta de los diferentes problemas para vincular la producción académica a la elaboración de políticas públicas -desde cuestiones sobre los tiempos que requieren uno y otro, los variados lenguajes y la accesibilidad de la información, hasta la delimitación de prioridades ${ }^{57}$ - así como la construcción de modelos para que el conocimiento sea "útil" a la política. Respecto del segundo nivel de la hipótesis sugerida, es interesante indagar cómo ese conocimiento presente en los regímenes de publicación centrales no termina de dar cuenta fehacientemente de aspectos centrales de "la" política del regionalismo; aspectos que - a la vez- sí son asumidos por el conocimiento del régimen periférico de publicación (que tiene un conocimiento "más próximo") pero que, por diferentes motivos, no logra ser "validado" por el régimen central. Al respecto, la desestimación de las explicaciones locales por la utilización de las propuestas de la red académica central se vincula a tres procesos: primero, buena parte de los acuerdos regionales encaminados desde los años noventa responden a la aplicación de visiones prescriptivas sobre el rol del regionalismo como catalizador de la globalización. Así, los mismos organismos regionales que postularon la integración de los sesenta - como CEPAL y el BID-INTAL - junto a los de la renovada estructura del orden económico mundial promovieron la firma de los acuerdos de regionalismo abierto a modo de inserción internacional competitiva en el nuevo marco multilateral y así cristalizar el proceso de reforma estructural por medio de un cerrojo jurídico-institucional. En segundo

\footnotetext{
57 Los estudios pioneros en este campo son los de Carol Weiss: WEISS, Carol H. "Research for Policy's Sake: The Enlightenment Function of Social Research." Policy analysis (1977): 531-545. WEISS, Carol H. "The Many Meanings of Research Utilization." Public administration review 395 (1979): 426-431. WEISS, Carol H. "Policy Research as Advocacy: Pro and Con." Knowledge and Policy 4 1-2 (1991): 37-55. WEISS, Carol H, Erin MURPHYGRAHAM, y Sarah BIRKELAND. "An Alternate Route to Policy Influence: How Evaluations Affect Dare." American Journal of Evaluation 261 (2005): 12-30. Desde allí el campo ha sido muy prolífico, excede los objetivos de este trabajo revisitarlos. En un estudio del que colaboramos, abordamos el nexo entre conocimiento y toma de decisiones para el caso de política comercial externa; incluyendo allí estudios de caso sobre MERCOSUR. Véase: BOTTO, Mercedes. Saber Y Política En América Latina: El Uso Del Conocimiento En Las Negociaciones Comerciales Internacionales. Buenos Aires: Prometeo Libros Editorial, 2007 [disponible en inglés: BOTTO, Mercedes. Research and International Trade Policy Negotiations: Knowledge and Power in Latin America. Vol. 1: Routledge, 2009].
} 
lugar, la estrategia de la UE de diseminar su forma de construir región estimuló un conjunto de estudios basados en el herramental de las Teorías Europeas de la Integración. La difusión de las cátedras Jean Monnet, la cooperación en educación superior y las acciones de diálogo político interregionales estimularon estas miradas ${ }^{58}$. La diplomacia científica encaminada por la UE fue productiva en la utilización de su herramental por parte de académicos (y decisores políticos) en la región, especialmente en la disputa global sobre las formas deseadas del regionalismo. En tercer lugar, las reglas de juego de la producción, circulación, consumo y validación de la producción de conocimiento académico en el mundo inciden en los límites y posibilidades para el desarrollo de miradas locales ${ }^{59}$. Efectivamente, es posible observar que las situaciones de dependencia académica se profundizan conforme se agranda la brecha de lo que se considera y se descarta como "ciencia de excelencia" en detrimento de las características propias de la producción, la divulgación y el uso de la ciencia en América Latina. El resultado es que buena parte de los y las académicas de la región se encuentren tensionados entre desarrollar un herramental teórico y metodológico propio -conforme los problemas cognitivos de la región- y validar su conocimiento conforme reglas diseñadas para contextos con diferentes problemas cognitivos. Al mismo tiempo, estas preocupaciones se anidaron a las discusiones sobre la colonialidad del saber y al centrismo occidental en la producción de conocimiento ${ }^{60}$, lo que dio paso a la visibilización de los aportes del Sur (global) en diferentes disciplinas, incluyendo las RI. En el siguiente acápite discutimos esto.

Con todo, los aportes de América Latina a las RI desde la IR como objeto de estudio son cuatro. Primero, la discusión sobre cesión y/o puesta en común de soberanía se establece en términos disímiles: diferenciar soberanía de autonomía al afirmar que la mejora de los márgenes de autonomía de los estados se alcanza con acuerdos de integración con diferentes grados o niveles de delegación de soberanía. Segundo, la integración (y/o el regionalismo) admite tipologías en función de los proyectos políticos que persiga, especialmente si la meta es construir autonomía, procurar desarrollo y defender los recursos naturales. Tercero, en relación a lo anterior, resulta más evidente la dependencia de los procesos políticos regionales respecto de los procesos políticos nacionales. Cuarto, la construcción identitaria regional parte

58 PERROTTA, Daniela, "La cooperación en mercosur: El caso de las universidades," en Temas 54, 2008. SANAHUJA, José Antonio, VÁZQUEZ, Sergio Tezanos, KERN, Alejandra y PERROTTA, Daniela, Más allá de 2015: Perspectivas y propuestas para la cooperación al desarrollo entre la unión europea y américa latina y el caribe (Hamburgo: Fundación EU-LAC, 2015). LENZ, Tobias, "Eu normative power and regionalism: Ideational diffusion and its limits," en Cooperation and Conflict 48.2, 2013.

59 PERROTTA, Daniela, Universidad...op.cit, VESSURI, Hebe, "The current internationalization of social sciences in latin america. Old wine in new barrels?," Internationalization of the social sciences and humanities, eds. M. KUHN y WEIDEMAN Bielefeld: Transcript, 2010, VESSURI, Hebe, GUÉDON, Jean-Claude y CETTO, Ana María, «Excellence or quality? Impact of the current competition regime on science and scientific publishing in latin america and its implications for development," en Current Sociology 62.5, 2014, KREIMER, Pablo, "¿dependientes o integrados?: La ciencia latinoamericana y la nueva división internacional del trabajo," en Nómadas.24, 2006, KREIMER, Pablo, "La evaluación de la actividad científica: Desde la indagación sociológica a la burocratización. Dilemas actuales," en Propuesta educativa 2.36, 2011, NAIDORF, Judith, "Actuales condiciones de producción intelectual. Una aproximación a la situación de los investigadores de las universidades públicas argentinas," Las condiciones de producción intelectual de los académicos en argentina, brasil y méxico, eds. Judith NAIDORF y Ricardo PÉREZ MORA Buenos Aires: Miño y Dávila, 2012, NAIDORF, Judith y PERROTTA, Daniela, "La ciencia social politizada y móvil de una nueva agenda latinoamericana orientada a prioridades," en Revista de la educación superior 44.174, 2015.

60 QUIJANO, Anibal, "La crisis del horizonte de sentido colonial/moderno/eurocentrado," en Casa de las Américas.259-260, 2010, MIGNOLO, Walter, La idea de américa latina Barcelona: Gedisa, 2007, LANDER, Edgardo, La colonialidad del saber: Eurocentrismo y ciencias sociales Buenos Aires: CLACSO, 2003. VIVARES, Ernesto, LOMBARDO, Paul Torres y CVETICH, Kristina, "Enfoques y cárceles conceptuales en el entendimiento de los nuevos regionalismos latinoamericanos," Desafíos estratégicos del regionalismo contemporáneo: Celac e iberoamérica, eds. Adrian BONILLA y Isabel ÁLVAREZ San José CR: FLACSO, 2014. 
de reconocer la existencia de una gran nación pluricultural latinoamericana y caribeña previa al proceso de conquista y colonización, las características de ese proceso y la peculiaridad de la conformación de los estados nación.

\section{Los aportes latinoamericanos al campo de estudio: ¿discusión disciplinaria o visibilización de la geopolítica del conocimiento?}

Se expuso que dos patrones de regionalismo y sus teorías avanzaron por carriles separados, posponiendo la crisis paradigmática una década, y que la agitación conceptual en el campo se despliega en dos ejes: (1) la discusión intra-campo para promover el diálogo entre ambos corpus teóricos para analizar el regionalismo como un fenómeno general pese a las peculiaridades de cada caso; (2) el debate disciplinar sobre el Occidentalismo prevaleciente y la demanda por valorizar los aportes locales en el estudio global de las Relaciones Internacionales.

La combinación de ambas cuestiones suscitó para la academia latinoamericana la visibilizacion de las explicaciones que surgieron para analizar el unionismo del siglo XXI, los proyectos creados, la refundación de los preexistentes y la incorporación de agendas de regulación. Esto también habilitó el reconocimiento de las formulaciones desarrolladas por las escuelas de la Teoría Social Latinoamericana y un inusitado interés de las mismas por académicos de RI "externos" al campo de estudios de la integración. Es decir, una parte del reconocimiento de estas producciones se explica por la popularidad que obtienen las experiencias de regionalismo latinoamericano y las propuestas originales para aprehenderlo, especialmente los que abrevan en la tradición del PLI. Pero también por un proceso reciente: la apropiación temática del regionalismo como estrategia de inserción en la discusión disciplinar de amplificación de las voces locales. Entonces, para los últimos, la revisión del Pensamiento Latinoamericano para la Integración y la actualización histórica de los fenómenos regionales sirve a los fines de posicionamiento disciplinar y búsqueda de reconocimiento y legitimidad en redes académicas centrales. Resulta alentador el estímulo al estudio del regionalismo como parte de la aportación local desde América Latina a las Relaciones Internacionales "globales", más es menester trascender la retórica de la visibilización y la liviandad de análisis en pos del desarrollo de un programa de trabajo riguroso para la construcción de teoría en Relaciones Internacionales como en el campo de la integración bajo preguntas significativas para estas latitudes; es decir, en base a nuestros problemas cognitivos y que puedan entrar en diálogo con los problemas cognitivos del mainstream disciplinar.

La construcción de las RI globales es una demanda disciplinar que se vincula al proceso de visibilización y denuncia del centrismo Occidental -y Westfaliano- desde posturas críticas marxistas y pos-coloniales, así como de la academia del Sur Global ${ }^{61}$ (de las redes periféricas, mejor dicho), un debate iniciado en otras Ciencias Sociales de regiones periféricas hace ya al menos dos décadas ${ }^{62}$. Efectivamente, estas críticas son pertinentes y el llamado a trascender

61 TICKNER, Arlene B, Los estudios internacionales en américa latina: isubordinación intelectual o pensamiento emancipatorio? Bogotá: Ediciones Uniandes, 2002, TICKNER, Arlene B y WAEVER, Ole, International relations scholarship around the world London: Routledge, 2009, ACHARYA, Amitav, "Global international relations (ir) and regional worlds a new agenda for international studies," en International Studies Quarterly 58.4, 2014, HURRELL, Andrew, "Towards the global study of international relations," en Revista Brasileira de Política Internacional 59.2, 2016, ACHARYA, Amitav y BUZAN, Barry, "Why is there no non-western international relations theory? An introduction," en International Relations of the Asia-Pacific 7.3, 2007.

62 LANDER, Edgardo, La colonialidad del saber: Eurocentrismo y ciencias sociales.op.cit, SOUSA SANTOS, Boavenura, Descolonizar el saber, reinventar el poder Montevideo: TRILCE, 2010. 
los clivajes Norte-Sur / Este-Oeste permite nutrir todo desarrollo disciplinar. La apelación a las Relaciones Internacionales globales fue planteada como una meta disciplinar para la incorporación perspectivas pluralistas e inclusivas, respetuosas de la diversidad, basadas en la historia mundial, integradora de regiones, regionalismos y estudios de área, para evitar el excepcionalismo63. Por su parte, otras posturas que reconocen las críticas señalan las limitaciones de las propuestas aún emergentes, ya que las Relaciones Internacionales no han sido trastocadas en sus presupuestos teóricos y metodológicos centrales ${ }^{64}$. En otras palabras, el debate sobre la "globalidad" de la disciplina - que ha ganado legitimidad y no ha de soslayarse- se dirime entre visibilizar un conjunto de demandas que no son novedosas para quienes han producido conocimiento desde posiciones periféricas ${ }^{65}$ y el llamado a mantener el conjunto de problemas y constructos centrales de la disciplina sin profundizar en las condiciones de producción de conocimiento que, efectivamente, cuentan con centros y periferias.

Reconocer los aportes de la academia latinoamericana al campo de estudios de la integración y, por traslación, a las RI forma parte de la actual tendencia en pos de la construcción de las RI globales. Esta visibilización coyuntural es el resultado del impacto de los patrones de producción, circulación y consumo de conocimiento a nivel global sobre la discusión disciplinar. La actual geopolítica del conocimiento ha posibilitado que la academia local incida sobre la academia mainstream y ello se derive en demandas por mayor inclusión en este circuito central. De la misma manera que la TSL se incorporó de manera dependiente al circuito científico central entre los años cincuenta y sesenta, la actual internacionalización de la ciencia social latinoamericana, en general, y de las RI, en particular, permite la visibilización de estas voces -ya sean conformistas, revisionistas y/o disidentes-. Esta mayor presencia de las academias locales en las discusiones centrales se encuentra estructurada en el régimen de validación del conocimiento académico, que es el que moldea la actual geopolítica del conocimiento66.

Las lógicas de la comunicación científica internacional que delimitan centros y periferias a partir del mercado de divulgación —eminentemente editorial- ${ }^{67}$ revitalizan las preguntas de

63 ACHARYA, Amitav, Global...op.cit., p. 3.

${ }^{64}$ HURRELL, Andrew, Towards...op.cit., p. 2.

65 Por citar un ejemplo, Luciano Tomassini en 1980 ya planteaba: "[el] aporte de Estudios Internacionales al desarrollo de la disciplina es el hecho de que la revista no ha sido tanto el resultado de una programación editorial de carácter impersonal, sino el fruto de un diálogo continuo entre un grupo de estudiosos de las relaciones internacionales de los países latinoamericanos interesados en compartir y debatir sus ideas, lo que ha hecho de ella una especie de "seminario permanente". En ocasiones, ese diálogo se expresó en la formación de agrupaciones de carácter estable, como el Programa de Estudios Conjuntos sobre las Relaciones Internacionales de América Latina (RIAL). Tres aportes se ha procurado efectuar a través de ese diálogo: [1] Promover el perfeccionamiento de los estudios internacionales como una disciplina académica y acentuar su vinculación con los problemas del desarrollo. [2] Mantener el análisis dentro de una perspectiva latinoamericana, no para evitar el examen de los intereses nacionales, sino por estimarse que América Latina debe actuar en el escenario internacional en forma concertada y que, por consiguiente, desde el punto de vista de las relaciones internacionales, la región constituye un legítimo campo de estudio. [3] Desarrollar, en la medida de lo posible, un enfoque transdisciplinario, más interesado en alcanzar una comprensión real de los problemas que en el avance formal de la disciplina, en un escenario internacional caracterizado por la creciente complejidad e interdependencia de los temas". TOMASSINI, Luciano. "Los Estudios ... op.cit., p. 545-546.

${ }^{66}$ La diseminación local de criterios de evaluación estandarizados internacionalmente incide en la promoción de un régimen de competencia global que promueve un modelo mainstream de internacionalización. PERROTTA, Daniela, Universidad...op.cit.

${ }^{67}$ Mercado editorial potenciado por la era digital que ha llevado a la masificación de revistas on-line que tienen 
la escuela latinoamericana en ciencia, tecnología y desarrollo respecto al lugar del científico periférico como "especialista local" relegado a la recopilación de datos y el desarrollo de estudios empíricos, mientras los científicos del circuito central son quienes pueden elaborar teorías y realizar un aporte al conocimiento con validez y alcance global ${ }^{68}$. Esta situación genera dos fenómenos en paralelo: primero, una apropiación liviana del corpus teórico del Pensamiento Latinoamericano para la Integración con pocas perspectivas de profundización, avance y/o crítica de los postulados de las escuelas que hemos señalado -ya que se cimienta en la auto-reproducción de una elite periférica internacionalizada-; segundo, la desestimación de las peculiaridades locales -que no encajan en los intereses del circuito de divulgación hegemónico- $y$, consecuentemente, desestimulan la construcción de teorías innovadoras, creativas y vinculadas con la realidad político-social local.

Así, buena parte de las críticas latinoamericanas al actual sistema de evaluación académica que impacta sobre el formato de divulgación pueden ser trasladadas a la discusión de la construcción de conocimiento efectivamente local y transformador en América Latina (sobre la integración, otros problemas de las Relaciones Internacionalesy las ciencias sociales en general): idioma de publicación y la posibilidad de alcanzar usuarios locales; las preguntas realizadas, las metodologías preferidas y las teorías sobre las que se abreva y su vinculación con la transformación social; la publicación en acceso abierto no comercial de calidad pero que no se encuentra visibilizado como tal por los sistemas científicos y universitarios, por los colegas y por los estudiantes de posgrado y grado. A lo que se adiciona la cuestión sobre el paper como el formato preferido para comunicar y divulgar, especialmente si se busca impactar en el sector público y/o en organizaciones sociales. A título ilustrativo: ¿es el inglés el idioma que genera más impacto en una región de habla hispana y lusófona?, especialmente, en tanto el español es el segundo idioma más hablado del mundo luego del chino; ¿importa tanto estudiar la governance en América Latina, más que otros temas? (tan sólo por abordar una temática popular hoy); ¿es el paper el mejor formato para que un hacedor de política tenga insumos para su actividad? Es más, la popularidad de revisitar el regionalismo latinoamericano como aporte local a las Relaciones Internacionales ¿podrá ser sostenible o quedará como moda coyuntural?

Estas -y otras - son preguntas que han de estructurar la reflexión sobre la producción local en Relaciones Internacionales, en general, y sobre integración regional, en particular. Analizar cómo se conforman las comunidades disciplinares locales en redes regionales, sus parámetros de funcionamiento y sus aportaciones autónomas; y desde aquí, cómo dialogan con redes académicas centrales -ya que las disciplinas no se internacionalizan ni regionalizan; son los programas de formación, de investigación y de vinculación los que experimentan y/o encaminan procesos de internacionalización y regionalización.

\section{Discusión}

Las Relaciones Internacionales han tenido un rol gravitante en el estudio de las regiones y la conformación de un campo de estudios de la integración regional, un campo que - por su

como efecto reforzar el núcleo de revistas centrales.

${ }^{68}$ KREIMER, Pablo, ¿Dependientes o integrados?: La ciencia latinoamericana y la nueva división internacional del trabajo. op.cit, VESSURI, Hebe, "Who is the social scientist in the twenty-first century?," Theories about and strategies against hegemonic social sciences, eds. M KUHN y Yazawam S 2013. 
objeto de estudio se caracteriza por la multidisciplinaridad-. En este trabajo argumentamos que la integración regional ganó popularidad en la disciplina en tres momentos a lo largo del desarrollo de procesos históricos de integración regional. En cada uno de estos momentos, desde las Relaciones Internacionales se generaron un conjunto de preguntas problemáticas que derivaron en interesantes respuestas teórico metodológicas que ampliaron las fronteras disciplinares. En este proceso, se construyeron dos canales paralelos dentro del mainstream para analizar la integración, primero, el regionalismo, luego y el esfuerzo de síntesis a partir del regionalismo comparado, en tercer término.

En cada uno de estos tres momentos, América Latina también produjo conocimiento sobre integración regional; ya sea por la aplicación de los enfoques y las teorías generadas en el mainstream como por la elaboración de propuestas teóricas más autonómicas. Un elemento central en la construcción de conocimiento "autonómico" para y sobre la integración regional refiere a la estrecha vinculación entre la academia y la política en una doble vía: primero, el pensamiento social latinoamericano estructura sus problemas cognitivos en base a los problemas propios de la región - que a lo largo del tiempo se han definido en términos de desarrollo económico integral, autonomía política y defensa de los recursos naturales-; segundo, los y las autores gravitantes del campo han tenido conexiones, vinculaciones y articulaciones cercanas con quienes toman decisiones (policy-makers). Adicionalmente, un aspecto a destacar es que los y las autores de este corpus de pensamiento pivoteaban entre diferentes "escuelas" (los desarrollistas, los dependentistas, los autonomistas, los de la ciencia para el desarrollo) y no eran, mayoritariamente, del campo disciplinar de las Relaciones Internacionales. Esto último se vincula con el desarrollo más tardío de la disciplina en la región pero especialmente con que la construcción de teoría se aglutinaba en torno a la ciencia social -genérica- como parte de su proceso de institucionalización (también acaecido en esos años).

Así, las contribuciones latinoamericanas al campo de estudios de la integración formaron parte de un proceso colectivo de producción de conocimiento relacionado al fortalecimiento de las Ciencias Sociales en la región desde una posición de autonomía académica en vistas a su usabilidad ya que se partía del supuesto de compromiso social con la resolución de problemas cognitivos locales y contextuales. Así, las explicaciones teóricas sobre lo regional en América Latina no surgen de las Relaciones Internacionales -si bien constituyen un aporte significativo que ha ganado atención en el último lustro- así como tampoco por un interés sobre la integración como objeto de estudio - al contrario, los primeros acuerdos de integración resultan de la implementación de recomendaciones de políticas a la condición de subdesarrollo-. La conformación de un corpus teórico sobre la integración se gesta en las redes regionales de académicos, intelectuales, investigadores, líderes políticos y sociales que buscaron resolver los problemas estructurales de América Latina. En estas redes regionales se consagraron los referentes de las Ciencias Sociales latinoamericanas y caribeñas desde perspectivas críticas, incluyendo a los del campo de estudios de la Ciencia Tecnología y Sociedad. En la medida en que el estudio se desarrolla a partir de problemas, los resultados se enfocan en propuestas de política.

A su vez, el desarrollo en cada uno de estos tres momentos -el inicial en los años cincuenta, el relacionado al proceso de globalización neoliberal de los años noventa y el 
iniciado a partir del primer lustro del Siglo XXI como parte del proceso de agitación conceptual dada la explosión y vitalidad de acuerdos regionales en todo el globo y especialmente en América Latina- se explica también por las reglas de juego de la actividad académica y científica: el régimen de evaluación y el proceso de internacionalización del conocimiento. Las conceptualizaciones y teorizaciones de los cincuenta están estrechamente vinculadas al proceso de institucionalización de la ciencia social latinoamericana; el incremento de la visibilidad de autores latinoamericanos desde el 2010 se explica por el régimen de publicación hegemónico estructurado. A ello se suma desde el tercer lustro del siglo XXI la discusión profunda encaminada desde el mainstream de las Relaciones Internacionales sobre el desarrollo de la disciplina y la demanda de apertura proveniente desde tres grandes ejes: los estudios de género, los estudios poscoloniales y la perspectiva del Sur Global -resumida así en este trabajo, pero cuya denominación y delimitación aún está sujeta a discusiones-. Estas nutridas discusiones motivaron la necesidad de articular el conocimiento producido y diseminado en el régimen competitivo de publicaciones y las redes periféricas, así como el diálogo entre posturas para enriquecer el desarrollo de la disciplina. Aún estamos transitando por este proceso y queda diferenciar cuánto de lo que se enuncia como latinoamericano en las redes centrales refiere a conceptualizaciones autonómicas y cuánto forma parte de un proceso de acomodamiento a las reglas de juego centrales para ganar visibilidad y prestigio en la profesión académica.

En este trabajo, la discusión que se intenta dejar planteada refiere a comenzar a preguntarnos cómo se produce conocimiento sobre Relaciones Internacionales en el área específica del campo de la integración regional. Esto implica analizar cómo se produce conocimiento en Relaciones Internacionales, la delimitación de centros y periferias y sus diferentes problemas cognitivos y las consecuentes situaciones de dependencia académica pero también una deriva interesante de este trabajo y que planteamos en términos de la discusión sobre la particularidad de la ciencia social latinoamericana (autonómica) vinculada a la articulación con "la" política y la "usabilidad" del conocimiento. En este punto, anticipamos una hipótesis de trabajo para desarrollar en ulteriores indagaciones: el campo de integración regional responde o reacciona ex-post a "la" política en América Latina. Como se adelantó, si se asume que nuestro campo de estudios ve gran parte de su desarrollo gracias a su capacidad de ofrecerse como una voz experta: ¿Por qué la voz experta no se materializa en la discusión del campo ex-ante a la práctica de las instituciones? ¿Qué voz experta está siendo un recurso cognitivo para las instituciones y por qué ese insumo no se plasma en las publicaciones más destacadas de ese campo académico? A modo tentativo, ensayamos posibles modelos de indagación para nuestra hipótesis: la ciencia de excelencia para los fenómenos políticos descriptos no es el principal insumo de los policy-makers locales (en sentido amplio) y/o la ciencia de excelencia asumida en los regímenes de publicación de mayor impacto del globo no representa a la voz experta, cuya presencia en la academia no se refleja en esas dinámicas.

Sobre estas cuestiones, es posible plantear la discusión sobre los colegios invisibles y la ciencia encargada. Para Wagner y Leydesdorff las motivaciones de la publicación científica no sólo se encuentran incorporarse a rankings de calidad, plantear reclamos en un campo, compartir ideas, establecer comunidad y atraer colaboradores; sino que también el proceso 
de crear redes y colaborar en ciencia - estos son los colegios invisibles-69. Para unirse a la red de colaboradores globales, resulta importante que el trabajo científico sea visible para los demás, identificable como miembro de un subcampo o comunidad y tener una presencia dentro del grupo. El proceso de convertirse en miembro participante del colegio invisible ha sido una característica central de la ciencia durante siglos. En el presente siglo, para los países en desarrollo que no tienen una historia de lazos estrechos con las comunicaciones científicas, resulta importante que los participantes del colegio invisible global tengan fácil acceso al conocimiento. Pero esta inclusión trasciende las técnicas asociadas a los números, la lectura de símbolos o el nivel de calidad aceptable en las bases de datos de clase mundial. Requiere de algo más. En este punto, para la academia latinoamericana que efectivamente busca resolver problemas cognitivos autonómicos, es relevante pensarlo desde la ciencia encargada: un tipo de ciencia que por sus vínculos inextricables con el poder político en los procesos de toma de decisiones regulatorias, ostenta formas y usos sociales divergentes de aquella ciencia reconocida como "tradicional", en el sentido de primordialmente dedicada a la investigación (Research Science). Sin embargo, estos vínculos aparecen velados por la forma idealizada de la actividad científica a nivel general ${ }^{70}$.

En el caso de las Relaciones Internacionales en América Latina y su vinculación con el estudio de la integración, su institucionalización se vincula fuertemente con esta necesidad de tener una "voz experta" que pueda generar conocimiento y organizar discusiones teóricas pero con un objetivo vinculado a "la práctica política". Por eso esta característica inicial de que los constructores del campo hayan sido académicos-políticos y que quienes producen conocimiento sobre integración en el siglo XXI no logre incorporarse en el régimen actual de publicación. En este último caso, no porque los y las productoras de conocimiento tengan vínculos estrechos con el poder político, sino que porque la motivación de sus trabajos refleja, en buena medida, la necesidad de pensar la usabilidad de ese conocimiento -y que muchas veces esa usabilidad se vincule a mejoras de política pública-. Efectivamente, esto abre el interrogante para pensar si los regímenes de publicación de la ciencia tradicional son diferentes a los de la ciencia encargada y, si lo son, cómo pueden articularse estas diferentes formas de publicación. Esto deja interesantes avenidas de indagación para aportar al debate general sobre las Relaciones Internacionales desde América Latina.

\section{Bibliografía}

ACHARYA, Amitav, "After liberal hegemony: the advent of a multiplex world order" en Ethics \& International Affaires, vol. 31, n 3, 2017, pp. 271-285.

ACHARYA, Amitav, "Comparative regionalism: a field whose time has come?" en The International Spectator, vol. 47, no 1, 2012, pp. 3-15.

ACHARYA, Amitav, "Global International Relations (IR) and regional worlds a new agenda for international studies" en International Studies Quarterly, vol. 58, no 4, 2014, pp. 647-659.

ACHARYA, Amitav y BUZAN, Barry, "Why is there no non-Western international relations theory? An introduction" en International Relations of the Asia-Pacific, vol. 7, no 3, 2007, pp. 287-312.

APONTE GARCÍA, Maribel, El Nuevo Regionalismo Estratégico. Los Primeros Diez Años del Alba-TCP,

69 WAGNER, Caroline S., y WONG, Shing Kit, "Unseen science? Representation of BRICS in global science" en Scientometrics, vol. 90, no 3, 2012, pp. 1001-1013.

70 SALTER, Liora, "Mandated science" en Mandated Science, Springer, 1988, pp. 186-209; JASANOFF, Sheila, "Science, politics, and the renegotiation of expertise at EPA" en Osiris, vol. 7, no 1, 1992, pp. 194-217; JASANOFF, Sheila, The Fifth Branch: Science Advisers as Policymakers, Harvard University Press, 2009. 
Consejo Latinoamericano de Ciencias Sociales - CLACSO, Buenos Aires, 2014.

APONTE GARCÍA, Maribel y AMÉZQUITA PUNTIEL, Gloria, El Alba-TCP. Origen y Fruto del Nuevo Regionalismo Latinoamericano y Caribeño, Concejo Latinoamericano de Ciencias Sociales (CLACSO), Buenos Aires, 2015.

BEIGEL, Fernanda, Autonomía y Dependencia Académica. Universidad E Investigación Científica en un Circuito Periférico: Chile y Argentina (1950-1980), Biblos, Buenos Aires, 2010.

BEIGEL, Fernanda, "Centros y periferias en la circulación internacional del conocimiento" en Nueva Sociedad, no 245, 2013, pp. 110-123.

BEIGEL, Fernanda, "Chile: Un Centro Periférico Para La Internacionalización De Las Ciencias Sociales Latinoamericanas Y La Construcción De Un Prestigio Académico Regional (1953-1973)." Revista de la Red Intercátedras de Historia de América Latina Contemporánea-Segunda Época 1 (2014): 101-105.

BEIGEL, Fernanda, "La Flacso Chilena Y La Regionalización De Las Ciencias Sociales En América Latina (1957-1973)." Revista mexicana de sociología 712 (2009): 319-349.

BERNAL-MEZA, Raúl. "El Regionalismo: Conceptos, Paradigmas Y Procesos En El Sistema Mundial Contemporáneo." Aportes para la Integración Latinoamericana Año XV, Nro. 21, 2009.

BHAGWATI, Jagdish, y Arvind PANAGARIYA. "Preferential Trading Areas and Multilateralism-Strangers, Friends, or Foes." Trading Blocs: Alternative Approaches to Analyzing Preferential Trade Agreements. Eds. Bhagwati, Jagdish, P Krishna y Arvind Panagariya. Cambridge: MIT Press, 1999. 33-100.

BIALAKOWSKY, Alberto, Marcelo ARNOLD-CATHALIFAUD, y Paulo Henrique MARTINS. El Pensamiento Latinoamericano: Diálogos En Alas. Sociedad Y Sociología. Buenos Aires: ALAS. CLACSO. Teseo, 2015.

BIANCULLI, Andrea C, y Andrea Ribeiro HOFFMANN. Regional Organizations and Social Policy in Europe and Latin America: A Space for Social Citizenship? : Springer, 2016.

BID, "El Nuevo Regionalismo En América Latina." Mas Allá De Las Fronteras: El Nuevo Regionalismo En América Latina. Ed. BID. Buenos Aires: Banco Interamericano de Desarrollo, 2002. 27-65.

BÖRZEL, Tanja A, y Thomas RISSE. The Oxford Handbook of Comparative Regionalism. Oxford University Press, 2016.

BÖRZEL, Tanja A., y Thomas RISSE. "From the Euro to the Schengen Crises: European Integration Theories, Politicization, and Identity Politics" en Journal of European Public Policy, vol. 25, no 1, 2018, pp. 83-108.

BÖRZEL, Tanja y RISSE, Thomas, "Diffusing (Inter-)Regionalism. The EU as a model of regional integration", Working Paper KFG The Transformative Power of Europe, 2009.

BÖRZEL, Tanja y RISSE, Thomas, "From Europeanisation to diffusion: introduction" en West European Politics vol. 35, no 1, 2011, pp. 1-19.

BÖRZEL, Tanja y RISSE, Thomas, When Europe Hits Home: Europeization and Domestic Change, Instituto Universitario Europeo, Florencia, 2000.

BÖRZEL, Tanja, "When europeanisation meets diffusion: exploring new territory" en West European Politics, vol. 35, no 1, 2011, pp. 192-207.

BOTTO, Mercedes, Research and International Trade Policy Negotiations: Knowledge and Power in Latin America, Routledge, 2009.

BOTTO, Mercedes, Saber y Política en América Latina: El Uso del Conocimiento en las Negociaciones Comerciales Internacionales, Prometeo Libros Editorial, Buenos Aires, 2007.

BOURDIEU, Pierre, El Oficio de Científico. Ciencia de la Ciencia y Reflexividad, Anagrama, Barcelona, 2003.

BOURDIEU, Pierre, Intelectuales, Política y Poder, Eudeba, Buenos Aires, 2009.

BOUZAS, Roberto, "El Mercosur diez años después. ¿Proceso de aprendizaje o déjà vu?" en Desarrollo Económico, vol. 41, no 162, 2001, pp. 179-200.

BRICEÑO RUIZ, José, "Del Regionalismo Estratégico al Regionalismo Social y Productivo. Las Transformaciones del Modelo de Integración en el Mercosur" en BRICEÑO RUIZ, José, El Mercosur Y Las Complejidades De La Integración Regional, TESEO, Buenos Aires, 2011.

BRICEÑO RUIZ, José, "Ejes y modelos en la etapa actual de la integración económica regional en América Latina" en Estudios Internacionales, vol. 45, no 175, 2013, pp. 9-39.

BRICEÑO RUIZ, José; RIVAROLA PUNTIGLIANO, Andrés y CASAS GRAGEA, Ángel, (eds.) Integración Latinoamericana y Caribeña. Política Y Economía, Fondo de Cultura Económica, Madrid, 2012.

BRICEÑO RUIZ, José y SIMONOFF, Alejandro, Integración y Cooperación Regional en América Latina. Una Relectura a Partir de la Teoría de la Autonomía, Biblos, Buenos Aires, 2015.

CAPORASO, James y KEELER, John, "The european community and regional integration theory", paper presented at the third biennial international conference of the European Community Studies Association, Washington D.C., 27-29 de mayo de 1993.

CARRANZA, Mario E., "Can Mercosur survive? Domestic and international constraints on Mercosur" en Latin American Politics and Society, vol. 45, no 2, 2003, pp. 67-103. 
CARRANZA, Mario E., "Resilient or declining? Latin American regional economic blocs in the postneoliberal era" en Latin American Politics and Society, vol. 56, n० 3, 2014, pp. 163-172.

CEPAL, Transformación Productiva con Equidad. La Tarea Prioritaria de América Latina y el Caribe en los Años Noventa, CEPAL, Santiago de Chile, 1990.

CLOSA, Carlos, "Mainstreaming regionalism" en EUI Working Paper 2015/12, 2015.

CHECKEL, Jeffrey, "The constructivist turn in international relations theory" en World Politics, vol. 50, no 2, 1998, pp. 324-348

CHECKEL, Jeffrey, "Social construction and integration" en Journal of European Policy, vol. 6, no 4, 1999, pp. 545-560.

DABÈNE, Olivier, "Explaining Latin Americas fourth wave of regionalism. Regional Integration of a third kind." Latin American Studies Association. Ed.

DABÈNE, Olivier, The Politics of Regional Integration in Latin America: Theoretical and Comparative Explorations. Palgrave Macmillan, 2009.

DAGNINO, Renato, Hernán THOMAS, y Amílcar DAVYT. "El pensamiento en ciencia, tecnología y sociedad en Latinoamérica: una interpretación política de su trayectoria." Redes III 7 (1996): 13-51.

DE LOMBAERDE, Philippe, "The good, the bad and the ugly in comparative regionalism: a comment on Sbragia" en JCMS: Journal of Common Market Studies, vol. 49, no 3, 2011, pp. 675-681.

DE LOMBAERDE, Philippe, et al. "The problem of comparison in comparative regionalism" en Review of International Studies, vol. 36, n 3, 2010, pp. 731-753.

DE MELO, Jaime, y Arvind PANAGARIYA. New Dimensions in Regional Integration. Cambridge University Press, 1995.

DUR, Andreas y GONZÁLEZ, Gemma, "¿Más hombres ciegos y más elefantes? Una revisión de la literatura más reciente sobre la integración europea", Working Paper no 233 del Institut de Ciències Polítiques i Socials de la Universidad Autónoma de Barcelona, 2004.

FABBRI, Claudia, "The constructivist promise and regional integration: An answer to "old" and "new" puzzles. The South American case", Working Paper no 182, Department of Politics and International Studies, University of Warwick, 2005.

FAWCETT, Louise, "Exploring regional domains: A comparative history of regionalism" en International Affairs, vol. 80, no 3, 2004, pp. 429-446.

FAWCETT, Louise y GANDOIS, Hélène, "Regionalism in Africa and the Middle East: Implications for EU Studies" en Journal of European Integration, vol. 32, no 6, 2010, pp. 617-636.

FAWCETT, Louise y HURRELL, Andrew, Regionalism in World Politics. Regional Organization and International Order, Oxford University Press, Nueva York, 1995.

FERRER, Aldo, "Densidad Nacional y Densidad Regional" en Revista Densidades, no 1, 2008, pp. 7-11.

FERRER, Aldo, Hechos y Ficciones de la Globalización: Argentina Y El Mercosur en el Sistema Internacional, Fondo de Cultura Económica, Buenos Aires, 1997.

FRANKEL, Jeffrey; STEIN, Ernesto y WEI Shang-Jin, "Trading blocs and the Americas. The natural, the unnatural, and the super-natural" en Journal of Development Economics, vol. 47, no 1, 1995, pp. 61-95.

GÓMEZ $\square$ MERA, Laura y MOLINARI, Andrea, "Overlapping institutions, learning, and dispute initiation in regional trade agreements. Evidence from South America" en International Studies Quarterly, vol. 58, no 2, 2014, pp. 269-281.

GÓMEZ MERA, Laura, "Explaining Mercosur's survival. Strategic sources of Argentine-Brazilian convergence" en Journal of Latin American Studies, vol. 37, no 1, 2005, pp. 109-150.

HAAS, Ernst. "International integration: The European and the universal process" en International Organization, vol. 15, no 3, 1961, pp. 366-392.

HAASTRUP, Toni, «EU as Mentor? Promoting regionalism as external relations practice in EU-Africa relations» en Journal of European Integration, vol. 35, no 7, 2013, pp. 785-800.

HABERMAS, Jurgen, Legitimation Crisis, Beacon Press, Bosto, 1973.

HAMERI, Shahar, "Beyond methodological nationalism, but whereto for the study of regional governance?" en Journal of International Affairs, vol. 63, no 3, 2009, pp. 430-441.

HAMERI, Shahar y JAYASURIYA, Kanishka, "Regulatory regionalism and the dynamics of territorial politics: the case of the Asia-Pacific region" en Political Studies, vol. 59, no 1, 2011, pp. 20-37.

HETTNE, Björn y SÖDERBAUM, Fredrik, "The new regionalism approach" en Politeia, vol. 17, n 3, 1998.

HETTNE, Björn y SÖDERBAUM, Fredrik, "Theorising the rise of regionness" en BRESLIN, Shaun, et. al. (eds.) New Regionalisms in the Global Political Economy. Theories and Cases, Routledge, Londres, 2002.

HETTNE, Björn, "The Europeanisation of Europe: endogenous and exogenous dimensions" en Journal of European Integration, vol. 24, no 4, 2002, pp. 325-340.

HETTNE, Björn, "The new regionalism: a prologue" en HETTNE, Björn; Andreas Inotai y SUNKEL, Osvaldo, (eds.) Comparating Regionalisms: Implications for Global Development, Palgrave, Basingstoke, 2000, pp. 22-42.

HURRELL, Andrew, "Explaining the resurgence of regionalism in world politics" en Review of Internation- 
al Studies, vol. 21, no 4, 1995, pp. 331-368.

HURRELL, Andrew, "Regionalism in theoretical perspective" en Fawcett, Louise y HURRELL, Andrew, Regionalism in World Politics, Oxford University Press, Oxford, 1995, pp. 31-71.

HURRELL, Andrew, "Towards the global study of International Relations" en Revista Brasileira de Política Internacional, vol. 59, no 2, 2016, pp 1-18.

JAGUARIBE, Helio, "Autonomía periférica y hegemonía céntrica" en Estudios Internacionales, vol. 12, no 46, 1979, pp. 91-130.

JAguARIBE, Helio, Desarrollo Económico y Desarrollo Político, EUDEBA, Buenos Aires, 1968.

JASANOFF, Sheila, "Science, politics, and the renegotiation of expertise at EPA" en Osiris, vol. 7, no 1, 1992, pp. 194-217.

JASANOFF, Sheila, The Fifth Branch: Science Advisers as Policymakers. Harvard University Press, 2009.

JETSCHKE, Anja y LENZ, Tobias, "Does regionalism diffuse? A new research agenda for the study of regional organizations" en Journal of European Public Policy, vol. 20, no 4, 2013, pp. 626-637.

KREIMER, Pablo, «¿Dependientes o integrados? La ciencia latinoamericana y la nueva división internacional del trabajo" en Nómadas, vol. 24, 2006, pp. 199-212.

KREIMER, Pablo, "La evaluación de la actividad científica: desde la indagación sociológica a la burocratización. Dilemas actuales" en Propuesta Educativa, no 36, 2011, pp. 59-77.

KUHN, Thomas, La Estructura de las Revoluciones Científicas, Fondo de Cultura Económica, México DF, 1971.

LANDER, Edgardo, La Colonialidad del Saber: Eurocentrismo y Ciencias Sociales. CLACSO, Buenos Aires, 2003.

LENZ, Tobias, "EU normative power and regionalism: ideational diffusion and its limits" en Cooperation and Conflict, vol. 48, no 2, 2013, pp. 211-228.

MALAMUD, Andrés, "Latin American regionalism and EU studies" en Journal of European Integration, vol. 32, n० 6, 2010, pp. 637-657.

MALAMUD, Andrés, "Overlapping Regionalism, no integration: conceptual issues and the Latin American experiences", EUI Working Paper, 2013/20, 2013.

MALAMUD, Andrés, "Presidential Diplomacy and the institutional underpinnings of Mercosur: an empirical examination" en Latin American Research Review, vol. 40, no 1, 2005, pp. 138-164.

MALAMUD, Andrés y SCHMITTER, Philippe, "La experiencia de integración europea y el potencial de integración del Mercosur" en Desarrollo Económico, vol. 46, no 181, 2006, pp. 3-31.

MANSFIELD, Edward D. y MILNER, Helen V., "The New Wave of Regionalism" en International Organization, vol. 53, no 3, 1999, pp. 589-627.

MIGNOLO, Walter, La Idea de América Latina, Gedisa, Barcelona, 2007.

MÍGUEZ, María Cecilia, "La Autonomía heterodoxa y la clasificación de las políticas exteriores en la Argentina" en Revista de Relaciones Internacionales, Estrategia Y Seguridad, vol. 12, no 2, 2017, pp. 207-229.

MOTTA VEIGA, Pedro da y RÍOS, Sandra, O Regionalismo Pós-Liberal, na América do Sul: Origens, Iniciativas e Dilemas, CEPAL, Santiago de Chile, 2007.

NAIDORF, Judith, "Actuales condiciones de producción intelectual. Una Aproximación a la situación de los investigadores de las universidades públicas argentinas" en NAIDORF, Judith y PÉREZ MORA, Ricardo, (eds.) Las Condiciones de Producción Intelectual de los Académicos en Argentina, Brasil Y México, Miño y Dávila, Buenos Aires, 2012.

NAIDORF, Judith y PERROTTA, Daniela, "La ciencia social politizada y móvil de una nueva agenda latinoamericana orientada a prioridades" en Revista de la educación superior, vol. 44, no 174, 2015, pp. 19-46

PAIKIN, Damián; PERROTTA, Daniela y PORCELLI, Emanuel, "Pensamiento latinoamericano para la integración" en Crítica y Emancipación, año VIII, no 15, 2016, pp. 49-80.

PANAGARIYA, Arvind, The New Regionalism in Trade Policy, World Bank Publications, 1992.

PEIXOTO, Juliana, y PERROTTA, Daniela, "El Mercosur en el nuevo escenario político regional: más allá de la coyuntura" en Desafíos, vol. 30, no 1, 2017, pp. 91-134.

PEIXOTO, Juliana, y PERROTTA, Daniela, "La cooperación en Mercosur: el caso de las universidades" en Temas, no 54, 2008, pp. 67-76.

PERROTTA, Daniela, "La integración regional en américa del sur como objeto de estudio: ¿en pos dela construcción de un campo? " en III Jornadas de Relaciones Internacionales, 2012.

PERRROTTA, Daniela, "El regionalismo de la educación superior en el proceso de integración regional del Mercosur: políticas de coordinación, complementación, convergencia y armonización en las iniciativas de acreditación de la calidad de carreras de grado (1998-2012)" Facultad Latinoamericana de Ciencias Sociales, sede académica Argentina, 2013.

PERROTTA, Daniela, "Universidad y geopolítica del conocimiento" en Revista Ciencias Sociales, no 94, 2017.

PERRROTTA, Daniela y PORCELLI, Emanuel, "'Regionalismo adjetivado": desafíos teóricos para la comprensión de los procesos de construcción de región en América Latina", Documento de Trabajo 
CEAP, Buenos Aires, 2016.

PHILLIPS, Nicola. "Regionalist governance in the new political economy of development:"relaunching" the Mercosur" en Third World Quarterly, vol. 22, no 4, 2001, pp. 565-583.

PUCHALA, Donald J. "Of blind men, elephants and international integration" en JCMS: Journal of Common Market Studies, vol. 10, no 3, 1971, pp. 267-284.

PUIG, Juan Carlos. "Integración y autonomía en América Latina en las postrimerías del siglo XX" en Integración Latinoamericana enero-febrero de 1989, pp. 40-62.

QUIJANO, Anibal, "La crisis del horizonte de sentido colonial/moderno/eurocentrado" en Revista de la Casa de las Américas, no 259-260, 2010, pp. 4-25.

QUILICONI, Cintia, "Atlántico versus pacífico: las alternativas en competencia de la integración comercial en América Latina" en Relaciones Internacionales, no 47, 2014, pp. 165-184.

QUILICONI, Cintia, "Competitive diffusion of trade agreements in Latin America" en International Studies Review, vol. 16, no 2, 2014, pp. 240-251.

REYES VELÁSQUEZ, Carlos, "Sociología del conocimiento: elementos introductorios desde Pierre Bourdieu para pensar los problemas de construcción y consolidación del campo comunicológico crítico" en Perspectivas de la Comunicación, vol. 6, no 2, 2013, pp. 20-27.

RIGGIROZZI, Pía y GRUGEL, Jean, "Regional governance and legitimacy in South America: the meaning of UNASUR" International Affairs 914 (2015): 781-797.

RIGGIROZZI, Pia y TUSSIE, Diana, "The rise of post-hegemonic regionalism in Latin America" en RIGGIROZZI, Pia y TUSSIE, Diana, (eds.) The Rise of Post-Hegemonic Regionalism. The Case of Latin America, Springer, Dordrecht, 2012, pp. 1-16.

SÁBATO, Jorge A., El Pensamiento Latinoamericano en la Problemática Ciencia - Tecnología - Desarrollo - Dependencia, MINCyT - Biblioteca Nacional, Buenos Aires, 2011.

SALTER, Liora, "Mandated science" en Mandated Science, Springer, 1988, pp. 186-209.

SANAHUJA, José Antonio, "Del 'Regionalismo abierto' al 'regionalismo post liberal'. Crisis y cambio en la integración en América Latina y el Caribe" en MARTíNEZ ALFONSO, Laneydi; PEÑA, Lázaro y VAZQUEZ MARTÍNEZ, Mariana, (eds.) Anuario de la Integración Regional de América Latina y el Gran Caribe, Coordinadora Regional de Investigaciones Económicas y Sociales-CRIES, n07, 2008-2009.

SANAHUJA, José Antonio, "Post-liberal regionalism in South America: the case of UNASUR", EUI Working Paper 2012/05, 2012.

SANAHUJA, José Antonio, et al. (eds.) Más Allá de 2015: Perspectivas y Propuestas para la Cooperación al Desarrollo entre la Unión Europea y América Latina y el Caribe, Fundación EU-LAC, Hamburgo, 2015.

SBRAGIA, Alberta, "Comparative regionalism: what might it be?" en JCMS: Journal of Common Market Studies, vol. 46, no 1, 2008, pp. 29-49.

SCHULZ, Michael; SÖDERBAUM, Fredrik y OJENDAL, Joakim, "Introduction: a framework for understanding regionalization" en SCHULZ, Michael; SÖDERBAUM, Fredrik, y OJENDAL, Joakim, (eds.) Regionalization in a Globalizing World: A Comparative Perspective on Forms, Actors, and Processes, Zed Books, Londres, 2001.

SIMONOFF, Alejandro, Teorías en Movimiento. Los Orígenes Disciplinares de la Política Exterior y sus Interpretaciones Históricas, Prohistoria Ediciones, Rosario, 2012.

SÖDERBAUM, Fredrik, "Consolidating comparative regionalism: from euro-centrism to global comparison", Paper for the GARNET 2008 Annual Conference, Sciences Po Bordeaux, 17 a 19 de septiembre de 2008.

SÖDERBAUM, Fredrik, "Introduction: theories of new regionalism" en Eds. SÖDERBAUM, Fredrik y SHAW, Timothy, Theories of New Regionalism. A Palgrave Reader, Palgrave, Basingstoke, 2003, pp. $1-21$.

SÖDERBAUM, Fredrik, Rethinking Regionalism. Rethinking World Politics, Palgrave, Nueva York, 2016.

SÖDERBAUM, Fredrik y SBRAGIA, Alberta, "EU studies and the 'new regionalism': what can be gained from dialogue?" en Journal of European Integration, vol. 32, no 6, 2010, pp. 563-582.

SOUSA SANTOS, Boavenura, Descolonizar el Saber, Reinventar el Poder, TRILCE, Montevideo, 2010.

TICKNER, Arlene B., Los Estudios Internacionales en América Latina: ¿Subordinación Intelectual o Pensamiento Emancipatorio? Ediciones Uniandes, Bogotá, 2002.

TICKNER, Arlene B., y WÆEVER, Ole, International Relations Scholarship around the World, Routledge, Londres, 2009.

TOMASSINI, Luciano, "Los estudios internacionales en América Latina: algunas contribuciones" en Estudios Internacionales, vol. 13, no 52, 1980, pp. 545-552.

TUSSIE, Diana y TRUCCO, Pablo, Nación y Región en América del Sur: los Actores Nacionales y la Economía Política de la Integración Sudamericana, Teseo, Buenos Aires, 2010.

VALDÉS GARCÍA, Félix, Antología del Pensamiento Crítico Caribeño Contemporáneo. West Indies, Antillas Francesas y Antillas Holandesa, CLACSO, Buenos Aires, 2017.

VARSAVSKY, Oscar, Ciencia, Política y Cientificismo, Centro Editor de América Latina (CEAL), Buenos 
Aires, 1969.

VAZQUEZ, Mariana, "El Mercosur social. cambio político y nueva identidad para el proceso de integración regional en América del Sur" en CAETANO, Gerardo, (ed.) Mercosur 20 Años, Centro de Formación para la Integración Regional - CEFIR, Montevideo, 2011, pp. 165-187.

VESSURI, Hebe, "The current internationalization of social sciences in Latin America. Old wine in new barrels?" en KUHN, Michael y WEIDEMANN, Doris, (eds.) Internationalization of the Social Sciences and Humanities, Transcript, Bielefeld, 2010, pp. 135-157.

VESSURI, Hebe, "Who is the social scientist in the twenty-first century?" en KUHN, Michael y YAZAWA, Shujiro, (eds.) Theories About and Strategies against Hegemonic Social Sciences, Columbia University press, 2013.

VESSURI, Hebe; GUÉDON, Jean-Claude y CETTO, Ana María, «Excellence or quality? Impact of the current competition regime on science and scientific publishing in Latin America and its implications for development" en Current Sociology, vol. 62, no 5, 2014, pp. 647-665.

VIVARES, Ernesto; TORRES LOMBARDO, Paul, y CVETICH, Kristina, "Enfoques y cárceles conceptuales en el entendimiento de los nuevos regionalismos latinoamericanos" en BONILLA, Adrián y ÁLVAREZ, Isabel, (eds.) Desafíos Estratégicos del Regionalismo Contemporáneo, FLACSO, San José, 2013, pp. 21-46.

WAGNER, Caroline S. y WONG, Shing Kit, "Unseen science? Representation of BRICS in global science" en Scientometrics, vol. 90, no 3, 2012, pp, 1001-1013.

WARLEIGH-LACK, Alex, "Towards a conceptual framework for regionalisation: bridging 'new regionalism' and 'integration theory'" en Review of International Political Economy, vol. 13, no 5, 2006, pp. 750-771.

WARLEIGH-LACK, Alex, y Luk VAN LANGENHOVE. "Rethinking EU studies: the contribution of comparative regionalism" en Journal of European Integration, vol. 32, nº 6, 2010, pp. 541-562.

WEISS, Carol H.; MURPHY-GRAHAM, Erin y BIRKELAND, Sarah, "An alternate route to policy influence: how evaluations affect dare" en American Journal of Evaluation, vol. 26, no 1, 2005, pp. 12-30.

WEISS, Carol H., "Policy research as advocacy: pro and con" en Knowledge and Policy, vol. 4, no 1-2, 1991, pp. 37-55.

WEISS, Carol H., "Research for policy's sake: the enlightenment function of social research" en Policy Analysis, vol. 3, no 4, 1977, pp. 531-545.

WEISS, Carol H., "The many meanings of research utilization" en Public Administration Review, vol. 39, no 5, 1979, pp. 426-431.

WIENER, Antje y DIEZ, Thomas, (eds.) European Integration Theory, Oxford University Press, Oxford, 2004. 


\section{RELACIONES INTERNACIONALES}

Revista académica cuatrimestral de publicación electrónica Grupo de Estudios de Relaciones Internacionales (GERI) Universidad Autónoma de Madrid, España

www.relacionesinternacionales.info

ISSN 1699 - 3950

ff facebook.com/RelacionesInternacionales

twitter.com/RRInternacional 